\title{
Monetary policy uncertainty spillovers in time and frequency domains
}

\author{
Rangan Gupta ${ }^{1}$, Chi Keung Marco Lau², Jacobus A. Nel ${ }^{3}$ and Xin Sheng ${ }^{4^{*}}$ (])
}

\section{*Correspondence:}

xin.sheng@anglia.ac.uk

${ }^{4}$ Lord Ashcroft International

Business School, Anglia

Ruskin University,

Chelmsford CM1 1SQ, UK

Full list of author information

is available at the end of the article

\begin{abstract}
We use the recently created monthly Interest Rate Uncertainty measure, to investigate monetary policy uncertainty across the US, Germany, France, Italy, Spain, UK, Japan, Canada, and Sweden in both the time and frequency domains. We find that the largest spillover indices are from innovations in the country itself; however, there are some instances where spillover indices between countries are large. These relationships change over time and we observe large variances in pairwise spillovers during the global financial crisis. We find that most of the volatility is confined to the crisis period. Policy makers should consider accounting for the spillovers from the US, Germany, France and Spain, as we found that they are the most consistent net transmitters of monetary policy uncertainty.
\end{abstract}

Keywords: Connectedness, Frequency domain spillover, Monetary policy uncertainty, Pairwise spillovers, Uncertainty spillover

JEL Classification: C32, D80, E52, F42

\section{Introduction}

Globalization has made countries more connected, which can lead to problems, as seen in the Global Financial Crisis (GFC). A seemingly unrelated event in one country or sector can be transmitted to a different country or sector, where the effects of these shocks are persistent and can be reinforced by other shocks. There are even spillovers between different types of uncertainty (risk), as Gabauer et al. (2020) found financial uncertainty transmits the shocks that drive economic and real estate uncertainty. Since the GFC, the literature on uncertainty spillovers has developed rapidly, to which we contribute by looking at monetary policy uncertainty spillovers between countries. Studying uncertainty and understanding the dynamics behind it gives more information to decision makers, which can reduce risk.

Most of the literature uses the Economic Policy Uncertainty (EPU) index created by Baker et al. (2016), where they searched newspaper articles for keywords. The majority of the literature (Colombo 2013; Balcilar et al. 2017a; Biljanovska et al. 2017; Caggiano et al. 2017; Antonakakis et al. 2018; etc.) only looked at EPU, while Gabauer and Gupta (2018) looked at monetary, fiscal, currency and trade uncertainty. They applied a TVPVAR to a dataset they compiled using the EPU and Arbatli et al. (2017).

(c) The Author(s) 2020. This article is licensed under a Creative Commons Attribution 4.0 International License, which permits use, sharing, adaptation, distribution and reproduction in any medium or format, as long as you give appropriate credit to the original author(s) and the source, provide a link to the Creative Commons licence, and indicate if changes were made. The images or other third party material in this article are included in the article's Creative Commons licence, unless indicated otherwise in a credit line to the material. If material is not included in the article's Creative Commons licence and your intended use is not permitted by statutory regulation or exceeds the permitted use, you will need to obtain permission directly from the copyright holder. To view a copy of this licence, visit http://creativecommons. org/licenses/by/4.0/. 
When investigating spillovers, the literature seems fond of the connectedness measure developed by Diebold and Yilmaz $(2009,2012,2015)$. It is used to test for connectedness in financial markets (Diebold and Yilmaz 2009, 2012, 2015; Tiwari et al. 2018) and EPU (Klößner et al. 2014; Yin et al. 2014; Balli et al. 2017; Liow et al. 2018). The methodology uses generalized forecast error variance decomposition to identify bi-directional spillovers, where the GARCH-in-mean VAR used by Nsafoah et al. (2019) can only identify one-directional flows.

There are also studies that analyze EPU with other methodologies, such as the work of Ajmi et al. (2014), which looked at Granger causality, both linear and non-linear. Gupta et al. (2016) used the Bayesian Additive Regression Trees (BART) algorithm to look at international uncertainty spillovers on Canada, while Gupta et al. (2018) investigated the effect of EPU on the business cycle for 48 US states and 51 metropolitan statistical areas. Çekin et al. (2019) used vine copulas to look at co-dependencies in Latin-American countries.

All the aforementioned studies find uncertainty spillovers, whether they be financial or economic or monetary. Rey (2015), through a VAR analysis found that monetary policy in a central country is one of the determinants in a global financial cycle. The monetary policy in the central country (currently the US) affects capital flows, credit growth in the international financial system and the leverage of global banks. Rey (2016) argued that the modern global financial cycle challenges the Mundellian trilemma since the exchange rate of a country is more important when it comes to maintaining a stable level. This is due to the dollar being widely used as a funding currency. Therefore, any changes in monetary policy in the US create movements in the dollar's strength, which will result in other countries applying monetary policy to maintain the exchange rate.

Miranda-Agrippino et al. (2015) found evidence of US monetary policy spillovers to the rest of the world when they studied the global financial cycle and world asset markets. They used a stylized model and found that tightening of US monetary policy leads to movements in various global financial variables, including cross-border credit and leverage. Their findings support the arguments made by Rey (2015), as the large amounts of dollar debt in other countries, and the close link between monetary policy and exchange rate, influence their monetary policy discretion.

Displaying the importance of monetary policy uncertainty spillovers, Gabauer and Gupta (2018) found that monetary policy uncertainty is the main driver of EPU, followed by fiscal, then currency and finally trade policy uncertainty. Using a DSGE model of the South African Economy, Balcilar et al. (2017b) found that monetary policy uncertainty can prolong weak economic activity, by suppressing inflation and output simultaneously, and can at times create unintended consequences.

The transmission mechanisms of monetary policy uncertainty are relatively unstudied, with Antonakakis et al. (2019) studying monetary policy spillovers under conventional and unconventional stances between US, UK, Euro area and Japan found that US and Euro area was the main transmitters of monetary policy spillovers and UK and Japan the main receivers. They also found that the largest spillovers from US were during times of unconventional times, noting the potential gains from policy coordination.

Gabauer and Gupta (2018) found that monetary policy uncertainty in the US drives trade policy uncertainty in Japan and vice versa. Balcilar et al. (2017b) found that 
monetary policy uncertainty suppresses inflation and output simultaneously, which leads to lower interest rates. This shows how monetary policy uncertainty affects other macroeconomic variables and can affect other economies not only through direct spillovers, but also through indirect channels.

We investigate the spillovers between countries resulting from monetary policy uncertainty and test whether the aforementioned only holds for spillovers from the US to the rest of the world. One similar study by Nsafoah et al. (2019) only looked at spillovers of US monetary policy uncertainty to an array of countries. We consider bi-directional spillovers and follow the literature in using Diebold and Yilmaz (2009, 2012, 2015). We then look at the spillovers in the frequency domain using Baruník and Křehlík (2018). The frequency analysis allows us to look at what happens to the spillovers between countries as time progresses using the full sample before we look at rolling window samples to graph the relationships. The frequency analysis is favorable, as it does not reduce the number of observations when quantifying the time-varying effects.

We use the Interest Rate Uncertainty index created by Istrefi and Mouabbi (2018) as a measure of monetary policy uncertainty, which has (to our knowledge) not been used in a similar study. Tran (2019) showed that there is a positive and significant correlation between the Monetary Policy Uncertainty (Baker et al. 2016) and Interest Rate Uncertainty, indicating that it can capture uncertainty surrounding monetary policy. We contribute to the empirical literature by applying two methodologies, not used in uncertainty spillovers for monetary policy, to a new measure for monetary policy uncertainty.

We find that there are large spillovers (compared to own spillovers) for some of the countries. The spillovers change over time, and most of these increase in size with the increase in time, starting from a shock. This points to a delayed reaction as the shock takes time to filter through the transmission mechanisms. The increase in bond maturity and forecast horizon leads to reduced uncertainty spillovers. We also find that the US is a net transmitter of uncertainty for most of the samples, but there are some instances where it is a net receiver.

The rest of the paper is structured as follows: Sect. 2 presents the data and methodology, Sect. 3 discusses the results and Sect. 4 concludes.

\section{Data and methodology}

\subsection{Data}

In this study, we investigate monetary policy uncertainty spillovers using the connectedness methodologies developed by Diebold and Yilmaz (2009, 2012, 2015) and Baruník and Křehlík (2018). The former analyzes the time domain and the latter analyzes the frequency domain. We use the Interest Rate Uncertainty (IRU) index created by Istrefi and Mouabbi (2018) as a measure of monetary policy uncertainty.

Istrefi and Mouabbi (2018) create the IRU by looking at 3- and 12-month forecasts from Consensus Economics surveys. This allows them to account for disagreement among forecasters and the perceived variability of future shocks. The second component is estimated using a stochastic volatility model, which results in a subjective interest rate uncertainty measure that allows for shocks to be time-varying and stochastic. They calculate the IRU for two bond maturity levels; 3 months and 10 years. This yields four IRU measures, which shows how uncertainty differs between the short and long term. 
We employ the IRU for all 9 countries (US, Germany, France, Italy, Spain, UK, Japan, Canada, and Sweden, denoted in this study, by U, G, F, I, S, UK, J, C, and Sw, respectively) and we analyze all of them. The index consists of two bond maturity levels, 3 months and 10 years, at both 3 - and 12 -month ahead forecast horizons. Therefore, $3 \mathrm{~m} 3 \mathrm{~m}$ would donate the interest rate uncertainty of a 3-month government bond yield, estimated at a 3-month ahead forecast horizon.

Due to data availability, we consider the following periods: for the $3 \mathrm{~m} 3 \mathrm{~m}$ dataset-Jan 1999 to Jul 2015, 3m12m-Jan 1999 to Oct 2014, 10y3m-Jan 1995 to Jul 2015 and for 10y12m-Jan 1995 to Oct 2014. For the two 10-year bond yield datasets, there is a missing observation for Japan in Jul 2005 and is omitted for all the countries in the 10-year datasets.

\subsection{Methodology}

Diebold and Yilmaz $(2009,2012,2015)$ proposed the methodology of measuring the interdependence of variables based on generalized forecast error variance decomposition in a vector autoregressive (VAR) model. The methodology calculates a spillover index in the generalized VAR setting of Pesaran and Shin (1998) in which forecast error variance decomposition is independent of variable ordering. In particular, consider an $\mathrm{N}$-variable VAR (p) system (in our case $N=9$ and $p=2$, selected by minimizing information criteria):

$$
Y_{t}=\sum_{i=1}^{p} \Psi_{i} Y_{t-i}+\epsilon_{t}
$$

where $Y_{t}$ is the $N \times 1$ vector of monetary policy uncertainty measures and $\Psi_{i}$ 's are the $N \times N$ parameter matrices. The disturbances $\left(\varepsilon_{t}\right)$ follow a white noise process. By covariance stationarity, the infinite-order moving average representation (MA) of the VAR (p) model in equation (1) exists and is given as

$$
Y_{t}=\sum_{i=0}^{\infty} A_{i} \varepsilon_{t-i}
$$

where $A_{i}=\Psi_{1} A_{i-1}+\Psi_{2} A_{i-2}+\ldots \Psi_{p} A_{i-p} . A_{0}$ is the $N \times N$ identity matrix, and $A_{i}=0$ for $i<0$.

In the MA representation, the generalized forecast error variance decomposition (GFEVD) at the H-step-ahead forecast horizon can be used to calculate the total, directional and pairwise spillovers of Diebold and Yilmaz (2009, 2012, 2015). Denoting GFEVD by $\vartheta_{i j}(H)$ as follows:

$$
\vartheta_{i j}(H)=\frac{\sigma_{j j}^{-1} \sum_{h=0}^{H-1}\left(e_{i}^{\prime} A_{h} \Omega e_{j}\right)^{2}}{\sum_{h=0}^{H-1}\left(e_{i}^{\prime} A_{h} \Omega A^{\prime}{ }_{h} e_{i}\right)}
$$

where $\sigma_{j j}$ is the standard deviation (SD) of the disturbances for the variable $j . \Omega$ is the (estimated) variance matrix of the error vector $\left(e_{i}\right)$, which is a selection vector corresponding to a vector of ones for the $i$ th variable and a vector of zeros otherwise. $\vartheta_{i j}(H)$ captures the contribution of variable $j$ to the variance of the forecast error of variable $i$, at 
horizon $\mathrm{H}$, providing a measure of pairwise spillovers from variable $j$ to $i$. The off-diagonal elements of the variance decomposition matrix $\vartheta(H)$ give the pairwise spillovers across variables. In contrast, the diagonal elements of $\vartheta(H)$ measure the contributions of shocks to variable $i$ to its own forecast error variance.

Since the rows of $\vartheta(H)$ do not necessarily sum to one, each element of the variance decomposition matrix can be normalized by the row sum:

$$
\widetilde{\vartheta}_{i j}(H)=\frac{\vartheta_{i j}(H)}{\sum_{j=1}^{N} \vartheta_{i j}(H)}
$$

where $\sum_{j=1}^{N} \widetilde{\vartheta}_{i j}(H)=1$ and $\sum_{i, j=1}^{N} \widetilde{\vartheta}_{i j}(H)=N . \widetilde{\vartheta}_{i j}(H)$ provides a measurement of pairwise spillovers from variables $j$ to $i$ at horizon $H$. This can be aggregated to calculate the total spillover index $C(H)$, which is defined as the share of variance in the forecasts contributed by errors other than its own, i.e., shocks to $Y_{j}$, for $i, j=1,2, \ldots, N$, and $i \neq j$.

$$
C(H)=\frac{\sum_{\substack{i, j=1 \\ i \neq j}}^{N} \widetilde{\vartheta}_{i j}(H)}{\sum_{i, j=1}^{N} \widetilde{\vartheta}_{i j}(H)} \times 100=\frac{\sum_{\substack{i, j=1 \\ i \neq j}}^{N} \widetilde{\vartheta}_{i j}(H)}{N} \times 100
$$

which captures the relative contributions to the total forecast error variance from spillovers of volatility shocks across variables.

The directional spillovers received by variable $i$ from all other variables $j$ are off-diagonal row sums (i.e., contributions from others) and are calculated as follows:

$$
D S_{i \leftarrow j}(H)=\frac{\sum_{\substack{j=1 \\ i \neq j}}^{N} \widetilde{\vartheta}_{i j}(H)}{N} \times 100
$$

and the spillovers transmitted by variable $i$ to all other variables $j$ are off-diagonal column sums (i.e., contributions to others) and are given by

$$
D S_{i \rightarrow j}(H)=\frac{\sum_{j=1}^{N} \widetilde{\vartheta}_{j i}(H)}{N} \times 100
$$

Based on the connectedness measures of Diebold and Yilmaz (2009, 2012, 2015), Baruník and Křehlík (2018) consider the frequency dynamics (e.g., the short, medium, and long terms) in the measurement of connectedness and propose a new approach to assess the connectedness of variables in the frequency domain. Baruník and Křehlík (2018) employ the spectral representation of GFEVD to define connectedness measures on different frequency bands of interest. For example, the aggregate measure on the given frequency band $d=(a, b)$ can be specified as

$$
\widetilde{C}^{d}=C^{d} \cdot \Gamma(d)
$$

where the spectral weight is $\Gamma(d)=\frac{\sum_{i, j=1}^{k}\left(\widetilde{\vartheta}_{d}\right)_{i, j}}{\Sigma_{i, j}(\vartheta)_{i, j}}=\frac{\sum_{i, j=1}^{k}\left(\widetilde{\vartheta}_{d}\right)_{i, j}}{k}$, and $C^{d}$ is the total connectedness measure on the connectedness tables $\left(\widetilde{\vartheta}_{d}\right)$ corresponding to the frequency band $d=(a, b)$. 
Table 1 Total connectedness summary

\begin{tabular}{lllll}
\hline & DY & BK-A & BK-B & BK-C \\
\hline $3 \mathrm{~m} 3 \mathrm{~m}$ & 66.15 & 45.82 & 63.00 & 73.51 \\
$3 \mathrm{~m} 12 \mathrm{~m}$ & 43.39 & 29.76 & 39.92 & 52.29 \\
$10 \mathrm{y} 3 \mathrm{~m}$ & 42.25 & 34.94 & 43.14 & 53.74 \\
$10 \mathrm{y} 12 \mathrm{~m}$ & 32.39 & 20.32 & 26.32 & 44.05 \\
\hline
\end{tabular}

Table 2 Net movements (TO-FROM)

\begin{tabular}{|c|c|c|c|c|c|c|c|c|}
\hline & DY & BK-A & BK-B & BK-C & DY & BK-A & BK-B & BK-C \\
\hline & U & & & & G & & & \\
\hline $3 m 3 m$ & 2.60 & -1.20 & -2.63 & 5.32 & -2.82 & 1.79 & -2.25 & -4.45 \\
\hline $3 \mathrm{~m} 12 \mathrm{~m}$ & 7.40 & 0.18 & 3.14 & 13.45 & 1.05 & 2.90 & 0.70 & -0.66 \\
\hline $10 y 3 m$ & -1.28 & 0.01 & -3.41 & -1.91 & 0.33 & -0.52 & 0.87 & 1.33 \\
\hline \multirow[t]{2}{*}{$10 \mathrm{y} 12 \mathrm{~m}$} & 2.40 & 0.98 & 1.22 & 4.04 & -1.43 & 1.10 & -0.95 & -3.52 \\
\hline & $F$ & & & & I & & & \\
\hline $3 m 3 m$ & 1.04 & 3.21 & 1.89 & 0.11 & 4.20 & 1.52 & 8.09 & 3.90 \\
\hline $3 \mathrm{~m} 12 \mathrm{~m}$ & -0.34 & -1.99 & 0.13 & 0.45 & -1.45 & -1.46 & 0.12 & -2.06 \\
\hline $10 y 3 m$ & 2.47 & 1.45 & 1.64 & 4.74 & -5.50 & 0.80 & -5.61 & -15.86 \\
\hline \multirow[t]{2}{*}{$10 \mathrm{y} 12 \mathrm{~m}$} & -1.57 & 0.14 & 0.12 & -3.66 & -2.40 & -0.66 & -2.65 & -3.53 \\
\hline & $S$ & & & & UK & & & \\
\hline $3 m 3 m$ & 5.58 & 3.27 & 5.61 & 6.28 & -5.21 & -2.68 & -7.67 & -5.29 \\
\hline $3 \mathrm{~m} 12 \mathrm{~m}$ & 2.89 & 0.64 & 4.64 & 3.53 & -3.73 & 1.73 & -2.14 & -7.62 \\
\hline $10 y 3 m$ & 2.22 & -0.38 & 4.37 & 4.99 & 0.70 & -0.16 & 1.44 & 1.61 \\
\hline \multirow[t]{2}{*}{$10 y 12 \mathrm{~m}$} & 0.93 & -0.77 & 0.55 & 2.37 & 2.85 & -1.94 & 1.97 & 6.80 \\
\hline & J & & & & C & & & \\
\hline $3 m 3 m$ & -5.35 & -0.63 & -2.86 & -7.58 & 7.05 & 0.23 & 5.81 & 9.57 \\
\hline $3 \mathrm{~m} 12 \mathrm{~m}$ & -0.74 & 0.06 & -1.11 & -1.07 & -2.15 & -0.33 & -1.30 & -3.58 \\
\hline $10 y 3 m$ & -0.69 & -0.38 & -0.93 & -1.04 & -0.58 & -1.54 & -0.27 & 0.78 \\
\hline \multirow[t]{2}{*}{$10 \mathrm{y} 12 \mathrm{~m}$} & -0.80 & -0.18 & -0.20 & -1.55 & 1.83 & 0.55 & 1.46 & 2.94 \\
\hline & Sw & & & & & & & \\
\hline $3 m 3 m$ & -7.09 & -5.60 & -6.00 & -7.88 & & & & \\
\hline $3 \mathrm{~m} 12 \mathrm{~m}$ & -2.95 & -2.98 & -4.18 & -2.44 & & & & \\
\hline $10 y 3 m$ & 2.34 & 0.71 & 1.89 & 5.35 & & & & \\
\hline $10 \mathrm{y} 12 \mathrm{~m}$ & -1.82 & 0.79 & -1.53 & -3.87 & & & & \\
\hline
\end{tabular}

Two estimation procedures were used at this point. First, we consider the full sample to look at the static relationships and then a 100-month rolling window sample is used to capture the time-varying aspects of the relationships (or the dynamic relationships). The former's results are tabulated, while the latter's results are shown in the figures.

\section{Results and discussion}

We report the estimation results for monetary policy uncertainty spillovers using the Diebold and Yilmaz $(2009,2012,2015)$ (hereafter DY) method in Tables 3, 5, 7, and 9 and the Baruník and Křehlík (2018) (hereafter BK) method in Tables 4, 6, 8, and 10. Table 1 gives the summary of the total spillovers of both methods, while Table 2 gives the net movements of all the countries for both methods. 
Table 1 shows the total spillover index, which is located in the lower right corner of Tables 3, 4, 5, 6, 7, 8, 9 and 10 (in Appendix). This measures the contributions of spillovers of shocks across countries to the total forecast error variance. The within connectedness (WTH in the BK tables) shows the spillovers within the frequency band and the frequency connectedness (ABS in the BK tables) splits the DY connectedness measure into the different frequency bands. $\mathrm{A}, \mathrm{B}$ and $\mathrm{C}$ correspond to the different panels in the BK tables in Appendix, where A is the short term (1-4 months), B is the medium term (4-12 months) and C the long term (12+ months), respectively.

Table 1 shows that connectedness decreases with a longer forecast horizon for both bond yields and both methodologies. The total connectedness increases as the frequency increases in the BK, with the long term being more connected. This indicates that there are larger monetary policy uncertainty spillovers 12 months and longer after a shock. This points to a time-varying nature in monetary policy uncertainty spillovers and should be accounted for when estimating a model that includes monetary policy uncertainty.

Table 2 shows the net movements for all the countries, where a positive value represents a net transmission and a negative value indicates a net reception. We calculate the net spillovers from Tables 3, 4, 5, 6, 7, 8, 9 and 10, which provide a decomposition of the total spillovers into those coming from (or going to) other countries. The elements in the last row (labeled "TO") represent directional spillovers transmitted by country $i$ (column) to all other countries, and those in the last column (labeled "FROM") are directional spillovers received by country $j$ (row) from all other countries.

We calculate the net movements by subtracting the uncertainty receptions from the transmissions (TO-FROM, in the tables). For example, in the DY results of the $3 \mathrm{~m} 3 \mathrm{~m}$ dataset, the directional spillover index from the US to other countries $(6.97 \%)$ is higher than the spillover index from other countries to the US (4.37\%), indicating that the US acts as a net transmitter of monetary policy uncertainty.

Despite the US being the central country, as mentioned by Rey (2015), there are some instances where the US is still a net receiver of uncertainty spillovers. The US, Germany, France, and Spain are the most consistent transmitters of monetary policy uncertainty, while Sweden and Japan are the most consistent receivers of uncertainty spillovers. Despite Japan receiving uncertainty spillovers most consistently, the size of the spillovers is negligible in all but the $3 \mathrm{~m} 3 \mathrm{~m}$ dataset. The US transmits the largest spillover, but Spain's spillovers have a larger mean, with a smaller variance.

In the results below we focus on the analysis of the $3 \mathrm{~m} 3 \mathrm{~m}$ dataset, but it can be replicated for all the other datasets. Entry $i, j(i \neq j)$ in Tables 3, 4, 5, 6, 7, 8, 9 and 10 represents the estimated contribution to the forecast error variance of country $j$ coming from shocks in country $i$. The diagonal element $(i=j)$ captures the fraction of the forecast error variance of country $i$ due to its own shocks.

From the DY uncertainty spillover results in Table 3, we observe that Spain delivers most spillovers to all other countries while Japan delivers the least. On average, innovations from Spain are responsible for $13.59 \%$ of the error variance in forecasting uncertainty of these countries, while only $1.11 \%$ comes from innovations to Japan. In contrast, the US receives the least of the spillovers from all other countries (4.37\%) and Germany receives the most (9.03\%). 
In the US, $60.71 \%$ of the error variance in forecasting its uncertainty stems from its own uncertainty. The estimated contributions to the forecast error variance of US uncertainty from other countries are relatively small, ranging from $0.49 \%$ (Italy) to $17.16 \%$ (Canada). On average, the spillover index for the whole system is $66.15 \%$, indicating that about two-thirds of forecast error variance come from spillovers during the whole sample period.

In Table 4, we find that the size of spillovers indices in the short term is much smaller than that stemming from DY. The innovations to the US contribute $14.06 \%$ (compared to $60.71 \%$ in DY) of error variance when it comes to forecasting its own uncertainty. The medium-term total spillover index is $63 \%$, which is higher than the short-term total spillover index, and close to that of DY. However, the own spillover index for the US is only $12.32 \%$. In the long term, our results show that the total spillover index is $73.51 \%$, indicating that nearly three-quarters of forecast error variance in the long term come from spillovers. Here, the own spillover index for the US is much higher than in the previous two periods, where $34.33 \%$ of uncertainty spillovers received is from its own innovations.

It is notable that the estimated contributions to the forecast error variance of US uncertainty stem mainly from its own innovations across all three frequency bands. This is also the case for the other countries as we move to the 10-year bond yield and a longer forecast horizon. Therefore, in the long run, a country's uncertainty is mainly influenced by its own uncertainty.

For the other bond yields and horizons, there are large spillover indices (relative to its own) between some of the European countries (France, Germany, Italy, Spain, Sweden, and UK). This is expected, as they have the same monetary authority (except the UK). This decreases with the longer horizon and with bond maturity, which points to a time-varying relationship between the countries. These relationships are analyzed below.

Following the DY and BK methods, we also analyze the dynamics of net pairwise spillovers over time using 100-month rolling window samples. The initial window period is from Jan 1999 to Apr 2007 for 3m3m and 3m12m, and Jan 1995 to Apr 2003 for $10 y 3 \mathrm{~m}$ and $10 \mathrm{y} 12 \mathrm{~m}$. Figures 1, 2, 3, 4, 5, 6, 7 and 8 present the time-varying behavior of net pairwise spillovers from May 2007, while Figs. 9, 10, 11, 12, 13, 14, 15 and 16 present the same for the $10 \mathrm{y} 3 \mathrm{~m}$ and $10 \mathrm{y} 12 \mathrm{~m}$ datasets from May 2003. The difference in start dates is due to the different time periods for the different datasets.

The crisis period can be seen at an approximate index of 20 (corresponding to Jan 2009) for the 3 -month bond yields and 68 for the 10 -year bond yields. The difference is due to the different start dates for the two bond yields. Data for the 10-year yields start 4 years prior to the 3 -month yields, so 48 should be added to that of the 3 -month yield to obtain the same date.

We find that net pairwise spillover effects are strong during the 2007-2008 Global Financial Crisis and the 2009 European Debt Crisis. Most of the relationships are more stable after the GFC. The pairwise spillovers in the US show that, after the crisis, there are instances where this factor is a negative net transmitter (i.e., a net receiver) of uncertainty. This is consistent with the results shown in Table 2, where the static analysis captured these net receptions. This is also consistent with the 
Pairwise spillovers
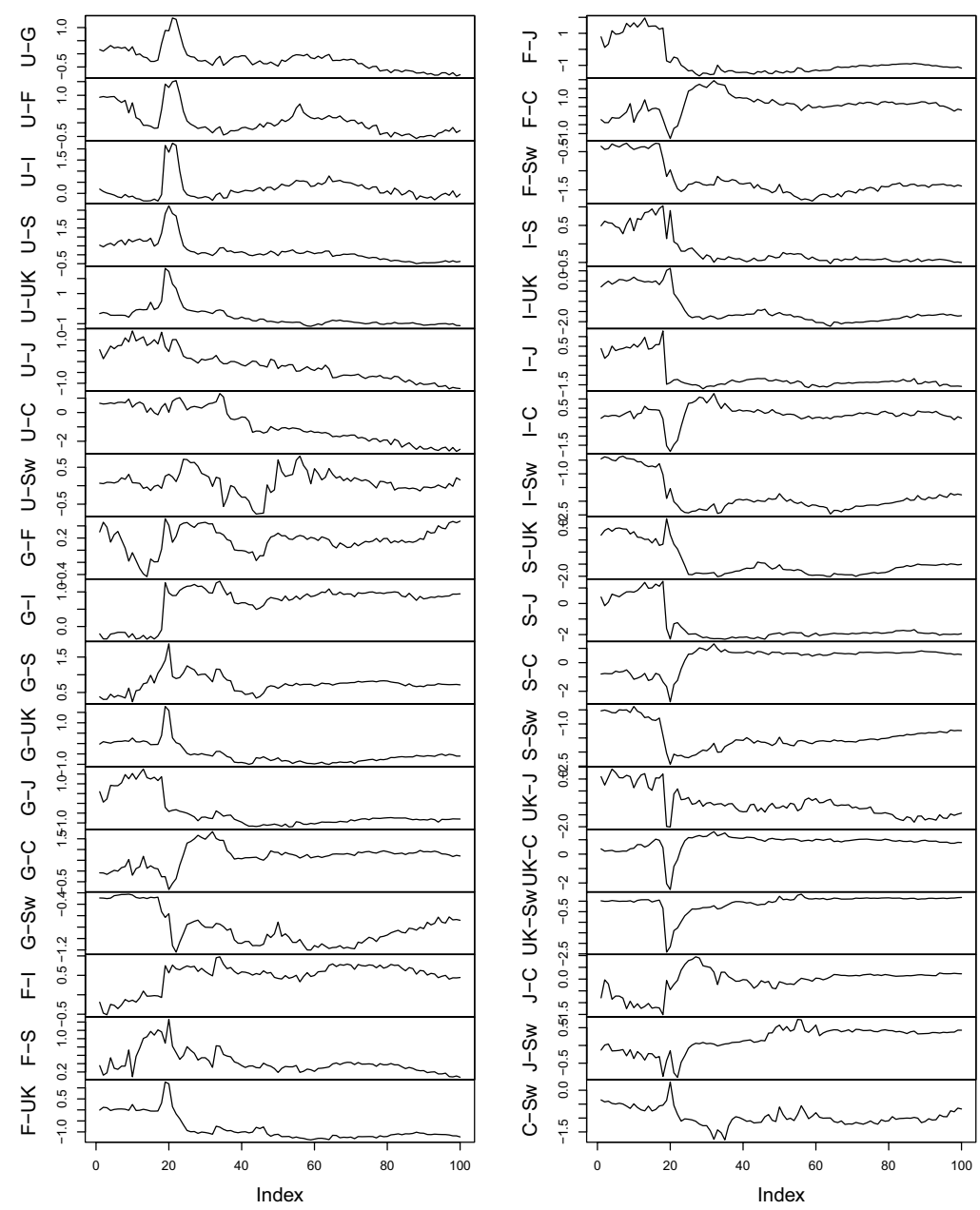

Fig. $13 m 3 m-D Y$

results of Diebold and Yilmaz (2015), where they consider the spillovers between the US and Euro area financial institutions. They find that after Lehman Brothers filed for bankruptcy, the US changed from a net transmitter to a net receiver of financial uncertainty.

Our results are consistent with the literature, despite using a different measure for uncertainty. It is clearly shown that there are bi-directional monetary policy uncertainty spillovers between countries. As our sample of countries is small due to data availability, it would be interesting to see how the results change when a greater number of developing countries were included. We suspect that the spillovers that they receive from other countries would be larger than those in our analysis (compared to own spillovers) due to their greater reliance on foreign currency denoted debt. 


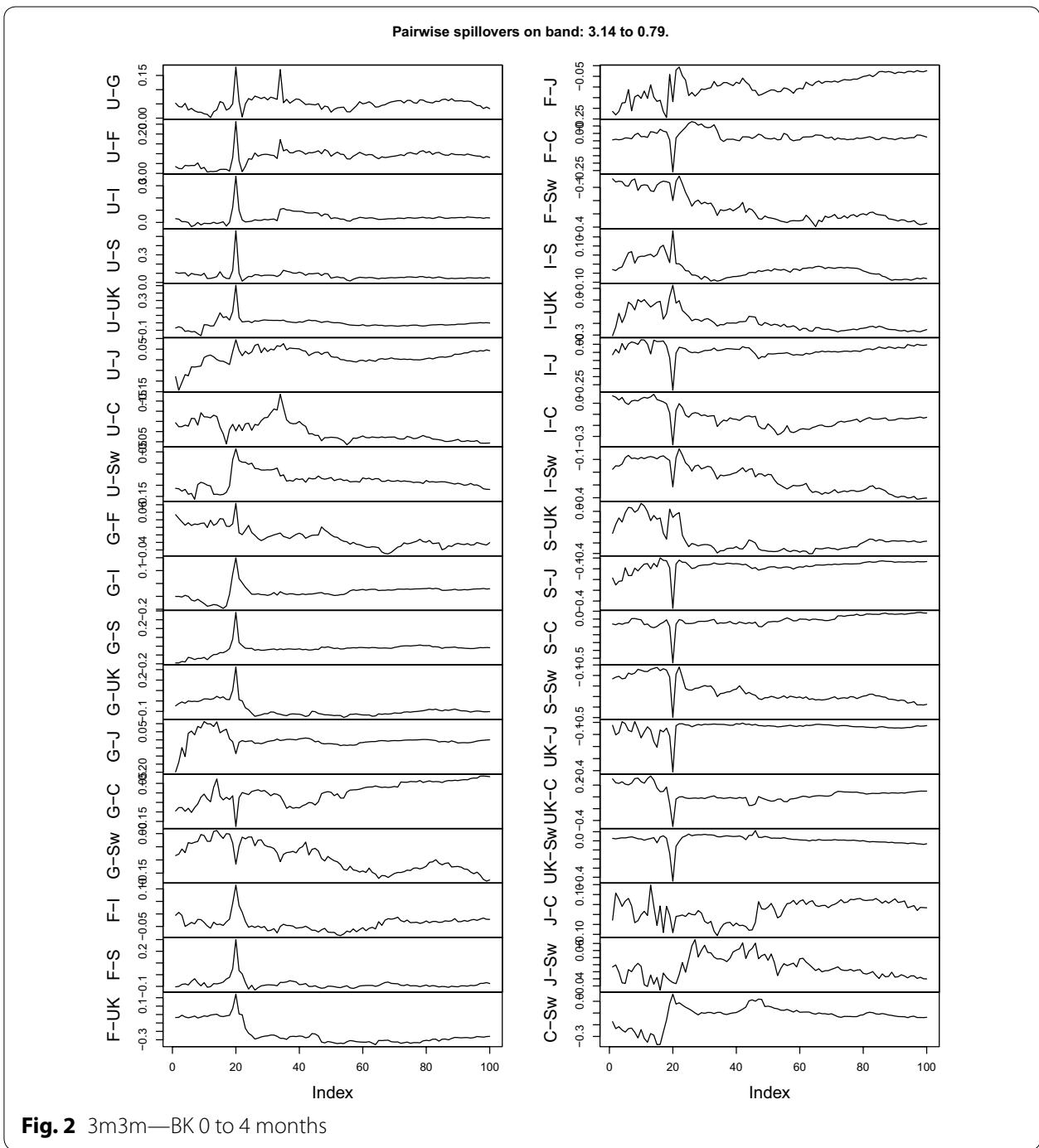

\section{Conclusion}

In this study, we use the Interest Rate Uncertainty measure from Istrefi and Mouabbi (2018) to look at monetary policy uncertainty (MPU) spillovers between the US, Germany, France, Italy, Spain, UK, Japan, Canada, and Sweden in both the time and frequency domains. For the time domain, we use the methodology created by Diebold and Yilmaz $(2009,2012,2015)$ and for the frequency domain, we use Baruník and Křehlík (2018), which builds on the former methodology. A frequency domain analysis is useful as it allows us to quantify the time-varying relationships at different frequencies, without reducing observations.

Most of the spillovers are from innovations in the country itself, but there are some instances of large spillovers between the countries examined. These spillovers vary with time, but the US, Germany, France, and Spain are consistent net transmitters over all the datasets. The spillovers between the European countries are small in the short and medium terms but large in the long term, in the 3-month bond yields at a 3-month forecast horizon dataset. This points to a delayed reaction as the innovations take time to 


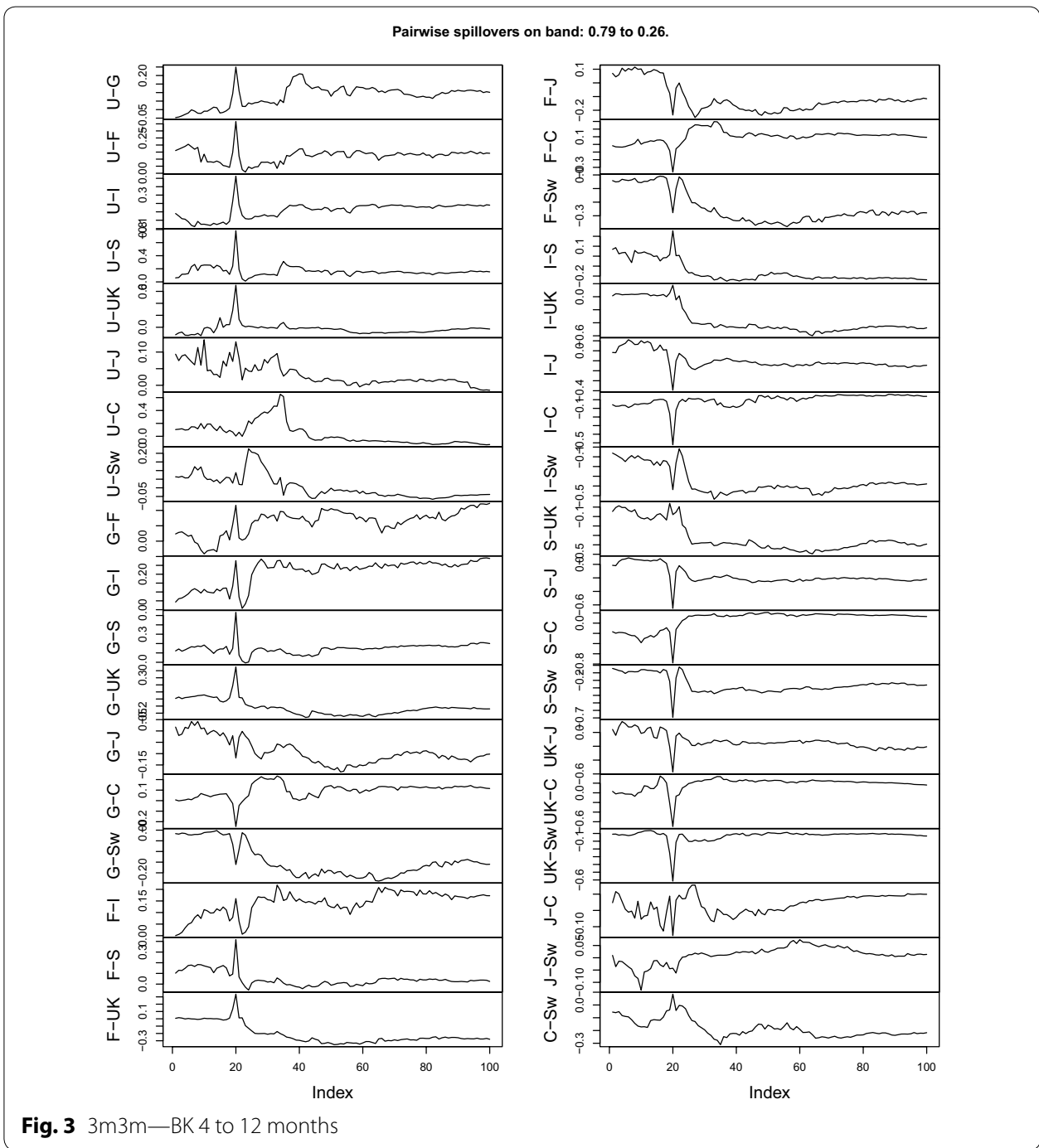

filter through the transmission mechanisms. Our results show that the increase in bond maturity and forecast horizon leads to reduced uncertainty spillovers. We also find that the US is a net transmitter of uncertainty for most of the samples, but there are some instances where it is a net receiver.

In the dynamic relationships, we find that most of the spillovers die down after the global financial crisis (GFC), decreasing in variance and moving to a level closer to zero. In some instances, the US becomes a net receiver of uncertainty, such as after the GFC in particular. This finding is consistent with the results found by Diebold and Yilmaz (2015).

Balcilar et al. (2017b) found that MPU suppresses inflation and output simultaneously, which leads to lower interest rates. This shows how MPU affects other macroeconomic variables and can affect other economies not only through direct spillovers, but also through indirect channels. We found that there are MPU spillovers between the countries in our sample. These two results create a problem for policy makers: they cannot simply dust consider just their own countries' policy uncertainty, and now also have 

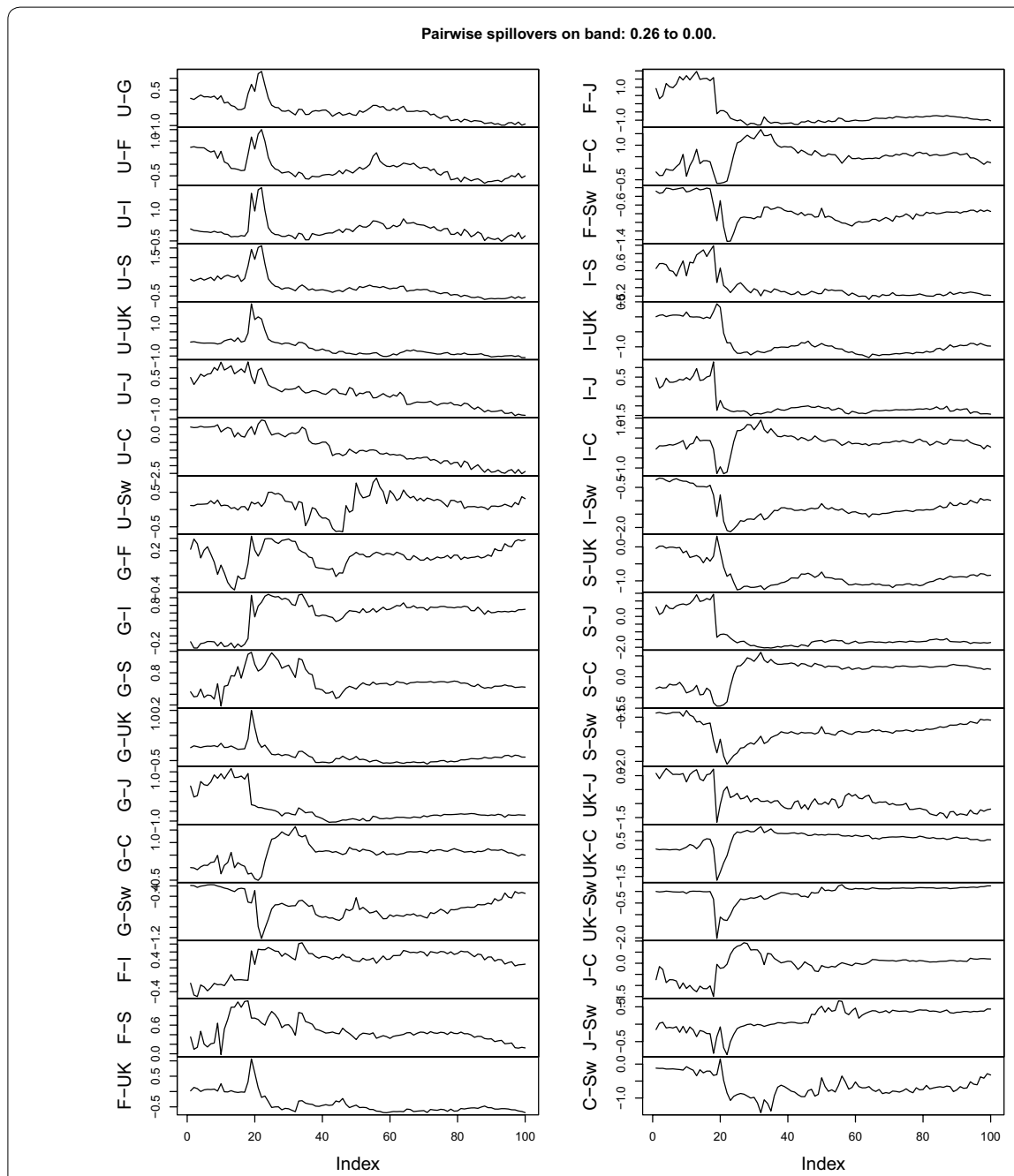

Fig. $43 m 3 m-B K 12$ months+

to account for the uncertainties in other countries. As uncertainty spillovers vary with time, their response cannot be the same every time. Policymakers should look at incorporating US, Germany, France and Spain's MPU in decisions, as they were consistent net transmitters of uncertainty.

MPU affects macroeconomic variables like inflation, output and the interest rate, which are important indicators to determine investment decisions and the timing of the investment. MPU is thus an important aspect to consider, as it could foreshadow problems or potential gains.

The analysis does not fully account for time-varying aspects of uncertainty spillovers, future studies can use methods that do, like TVP-VAR instead of a normal VAR in the analysis. Future studies in this area can also look at the bi-directional spillovers between developed and developing countries. As suggested by Rey (2015), the developing world could have even less monetary policy discretion than the developed world. The developing world may have a greater reliance on foreign denoted debt, and the spillovers to these countries would be larger than spillovers to developed countries. Another area that is still 


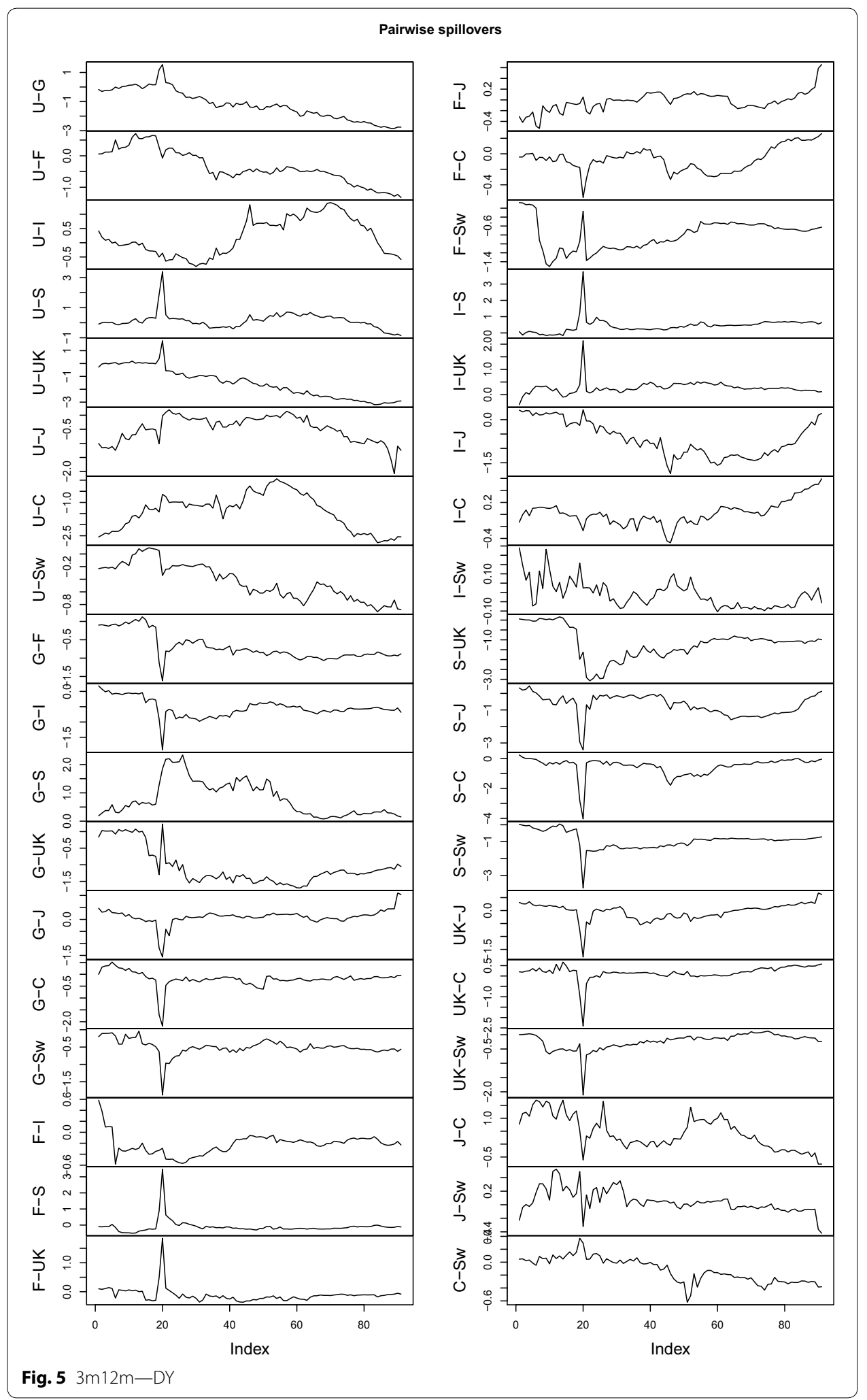




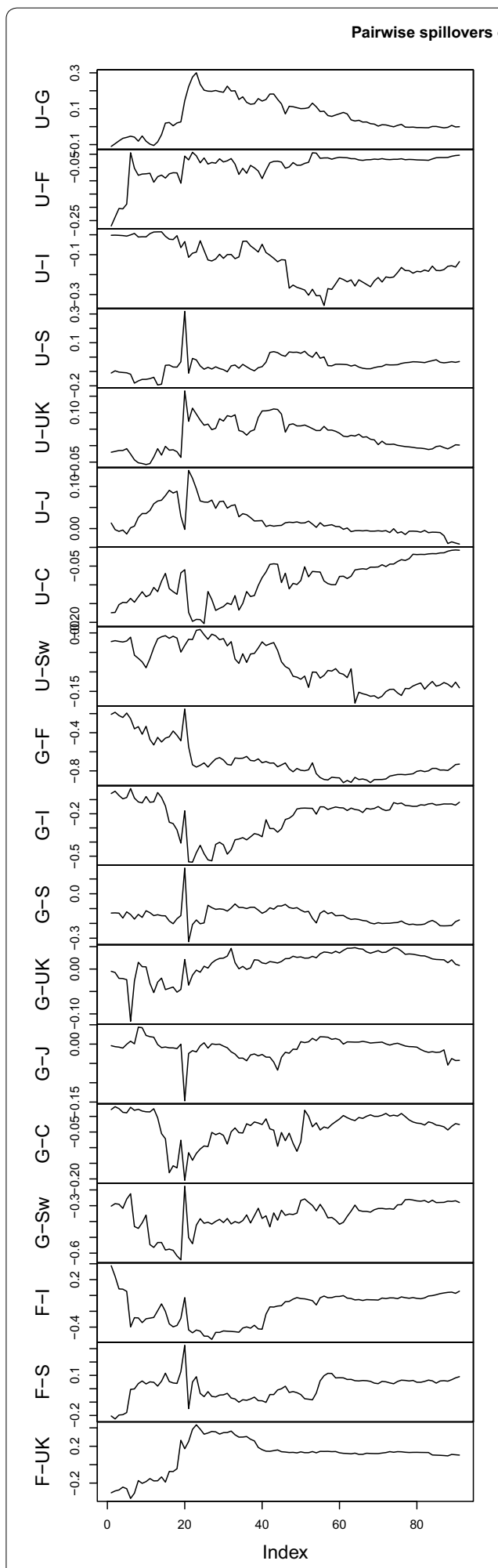

Fig. $63 m 12 m-B K 0$ to 4 months

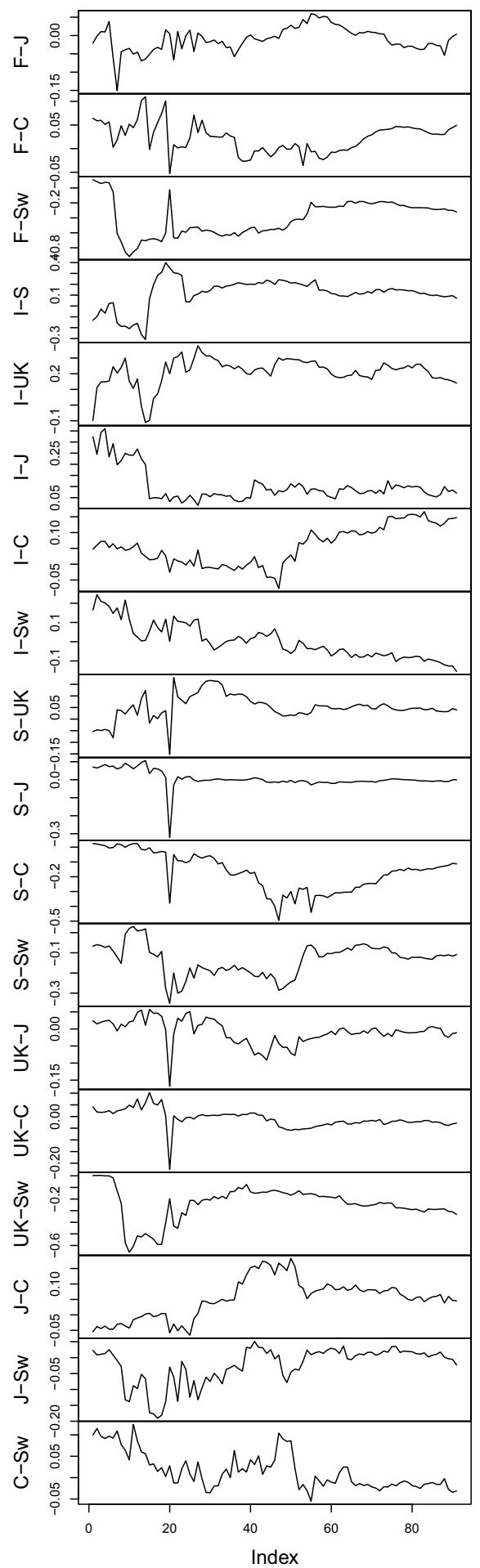




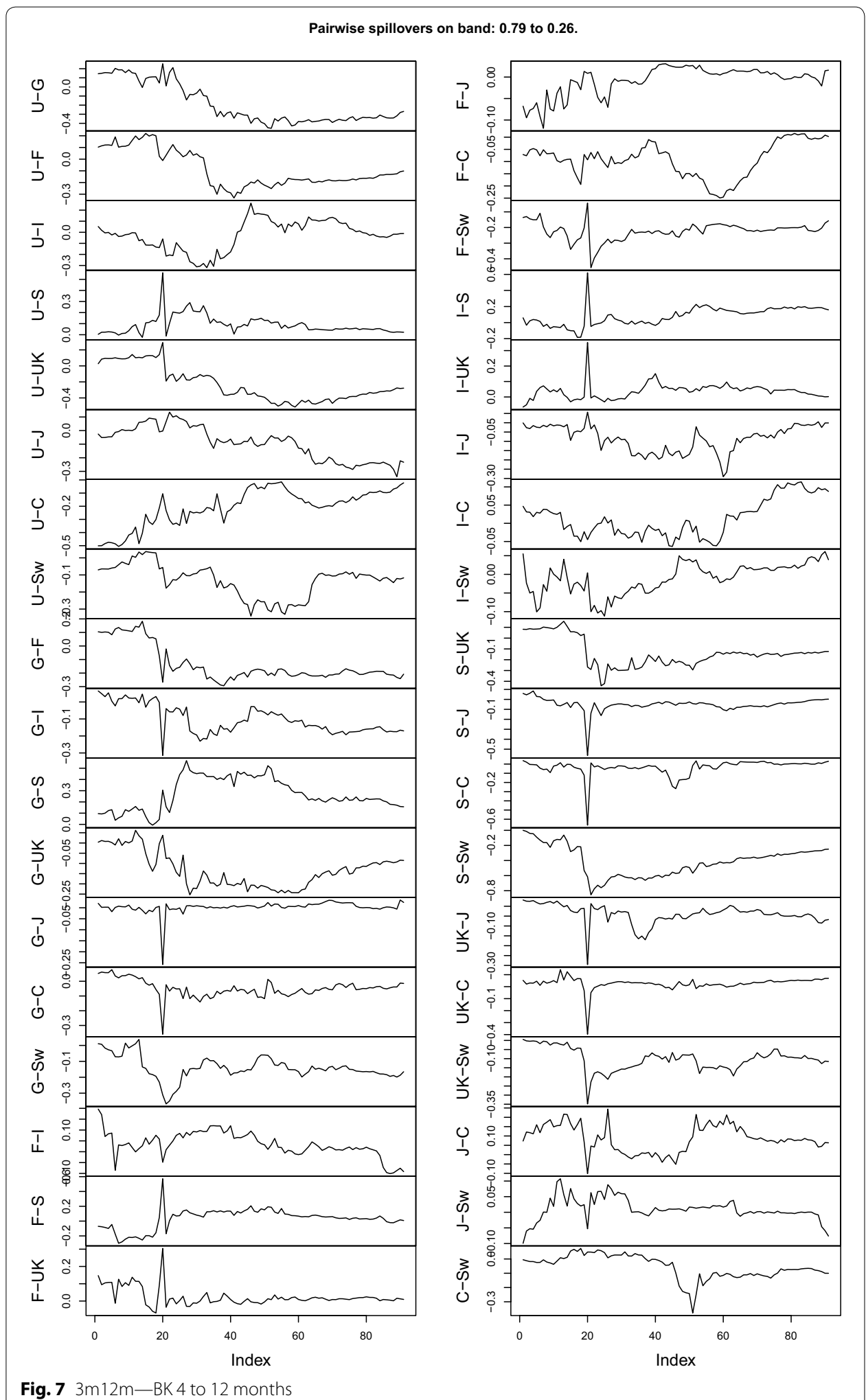




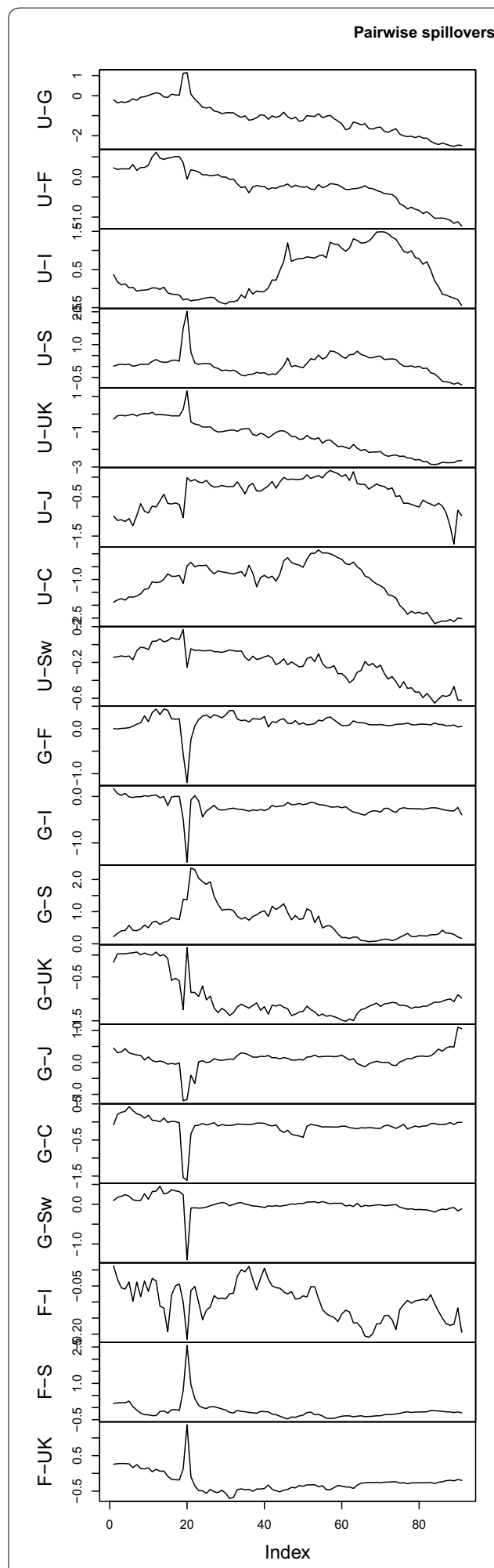

Fig. $83 m 12 m-B K 12$ months+

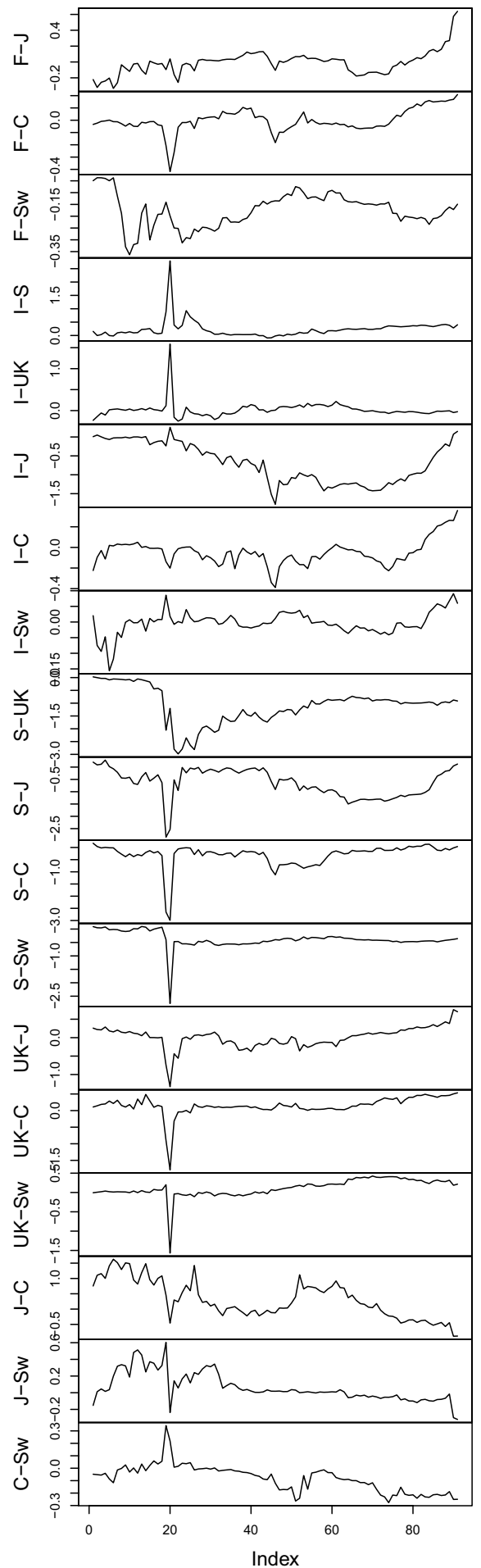




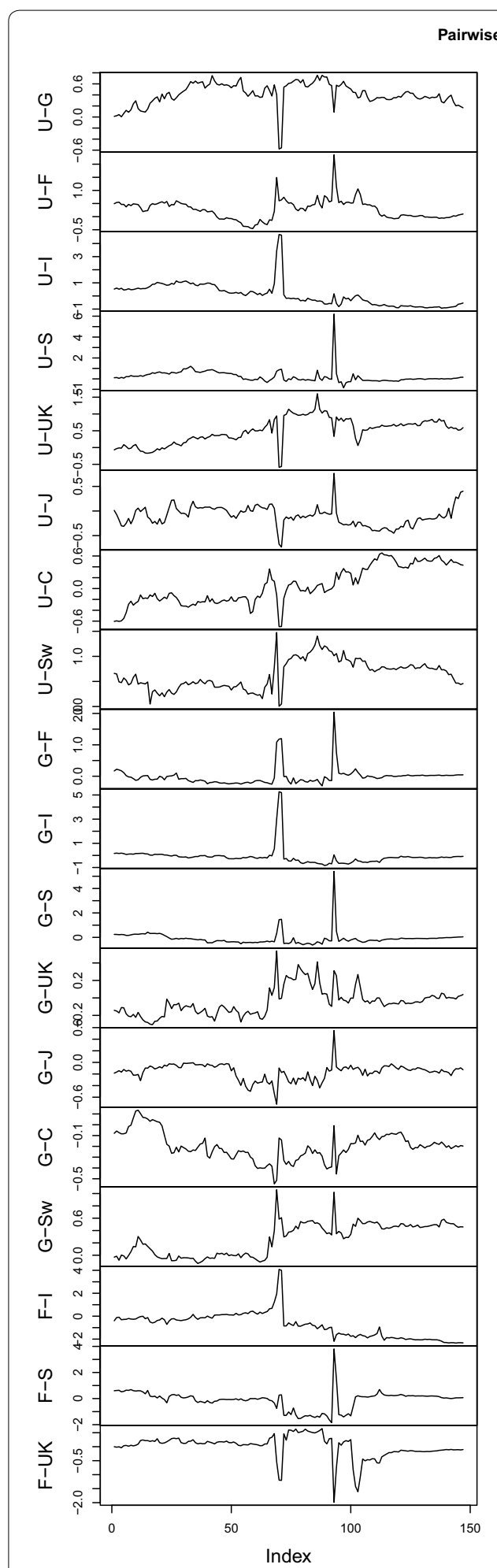

airwise spillovers

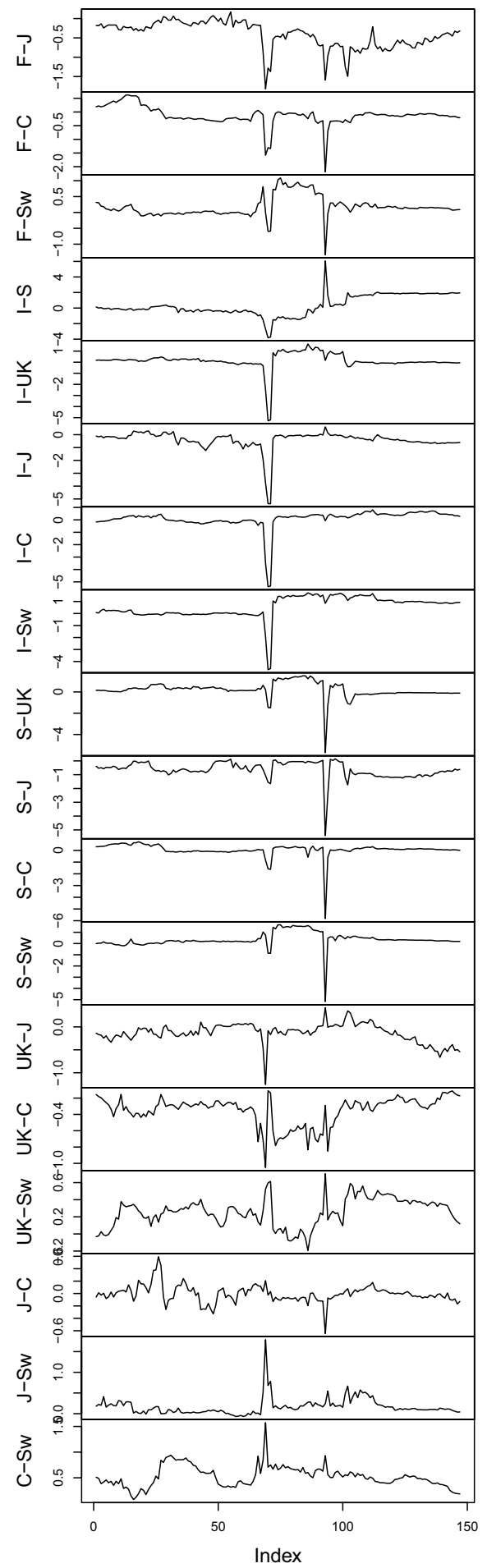

Fig. $910 y 3 m-D Y$ 
Pairwise spillovers on band: 3.14 to 0.79 .
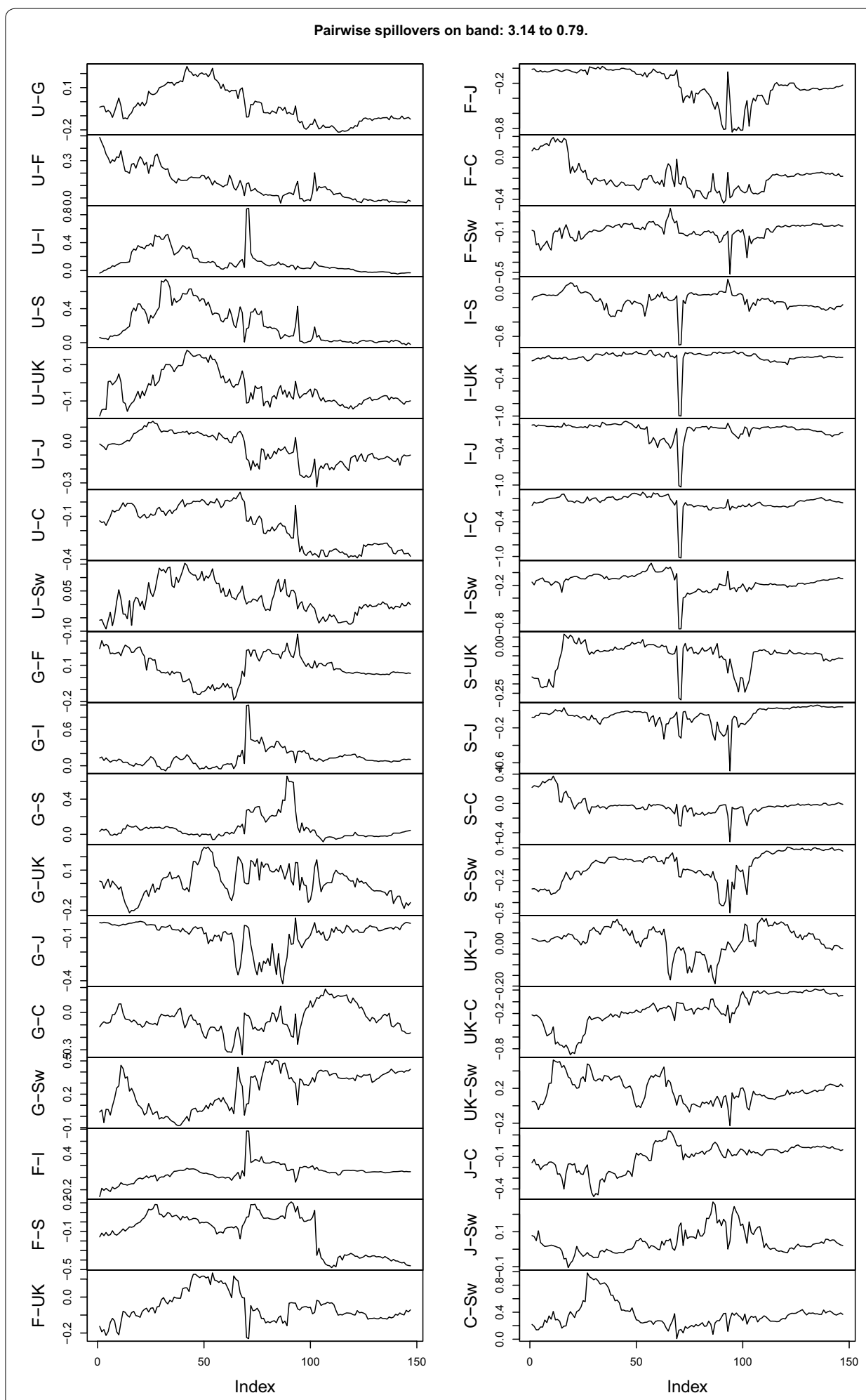

Fig. $1010 y 3 m-B K 0$ to 4 months 


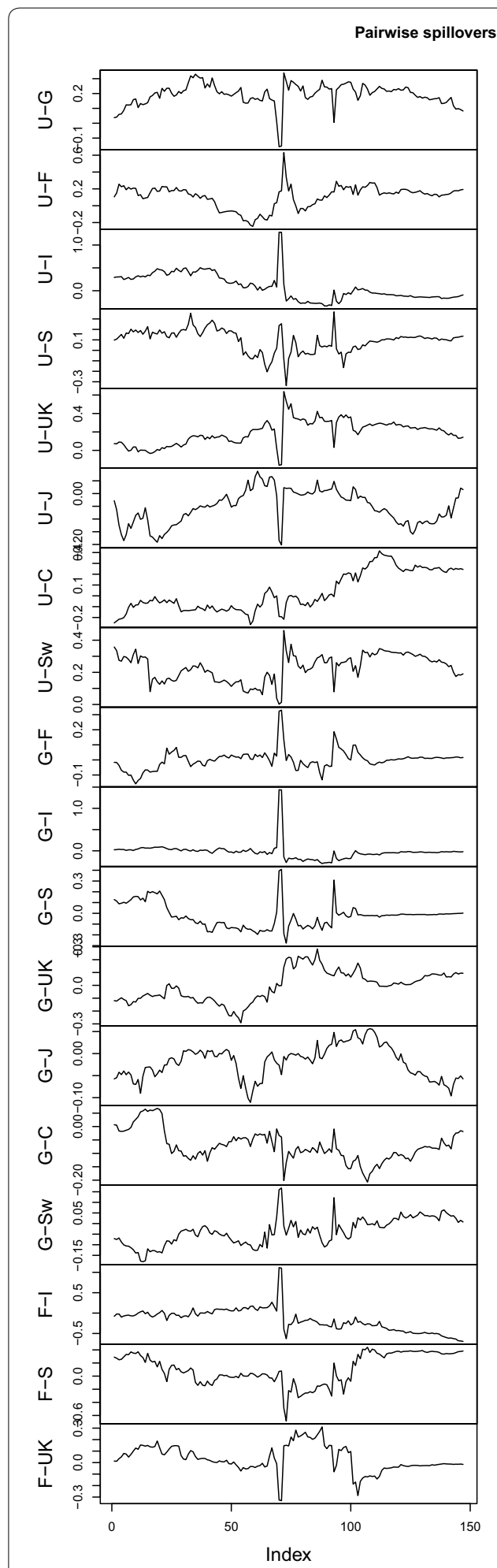

Fig. $1110 y 3 m-B K 4$ to 12 months 


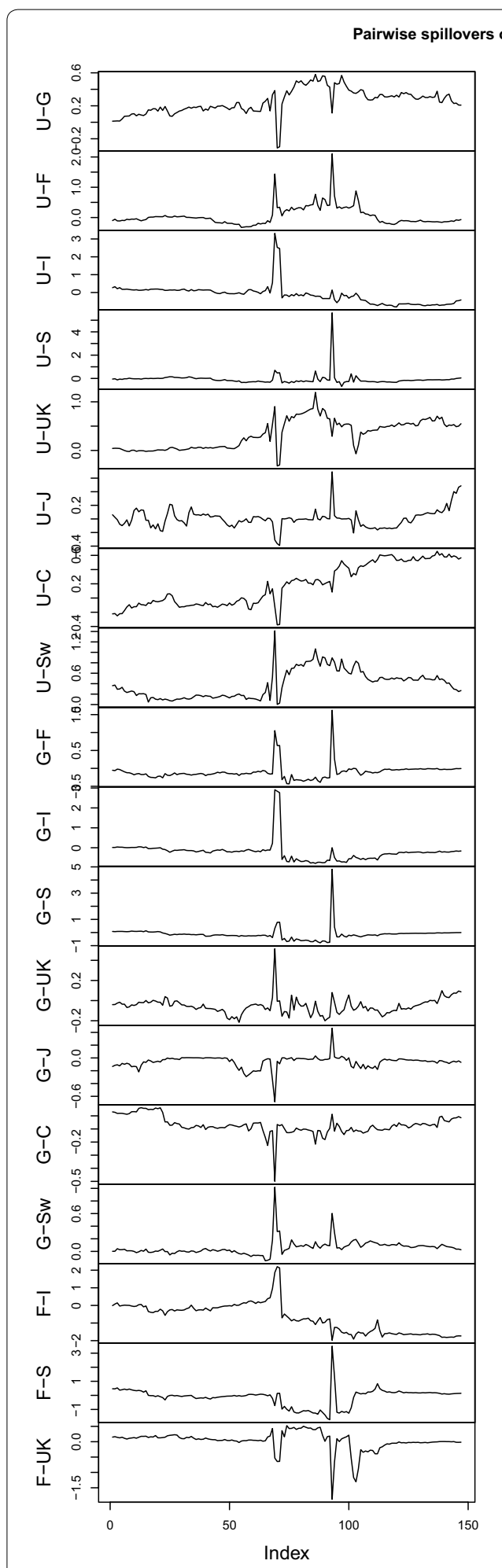

Fig. 12 10y3m-BK 12 months+ 
Pairwise spillovers
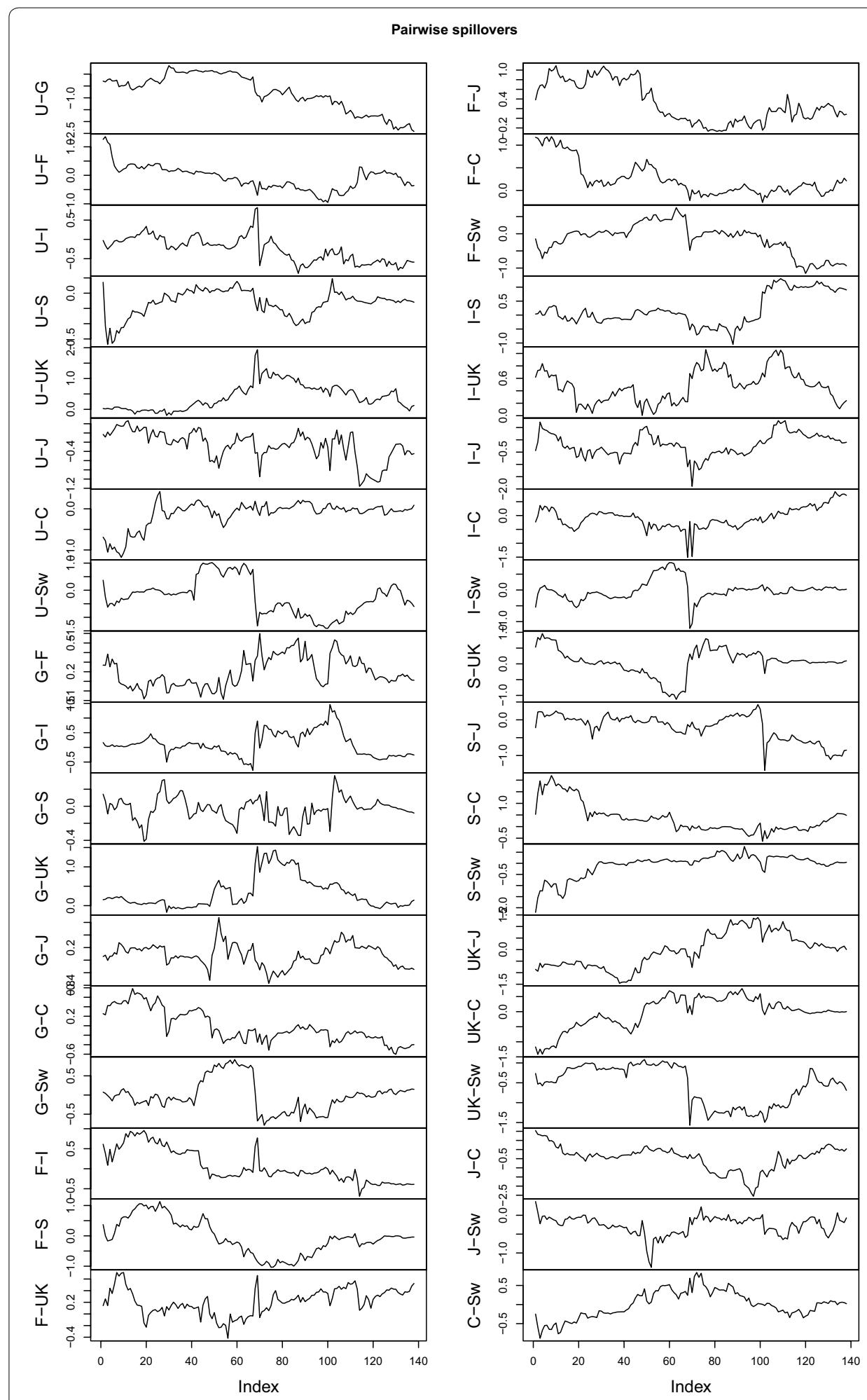

Fig. $1310 y 12 m-D Y$ 


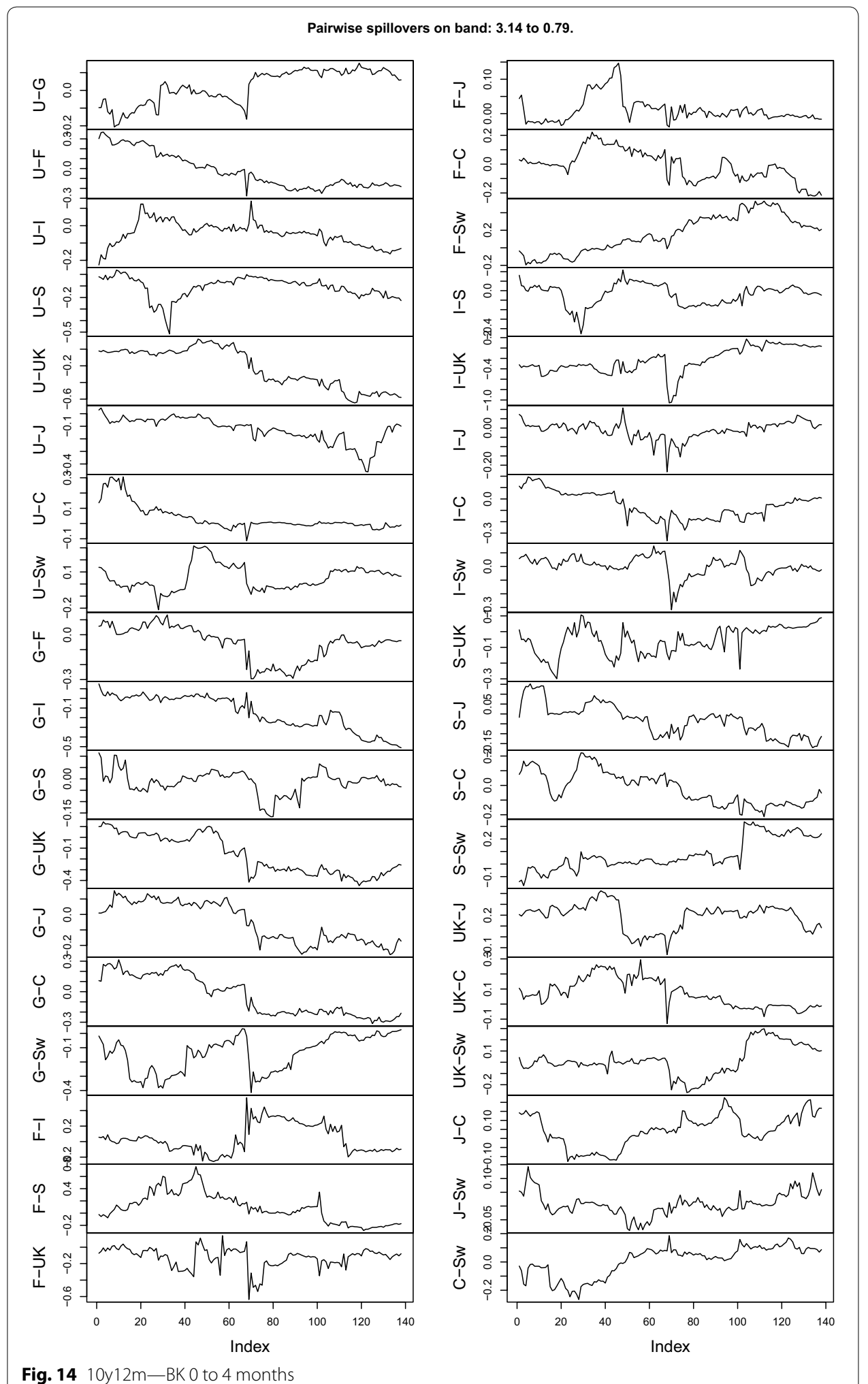



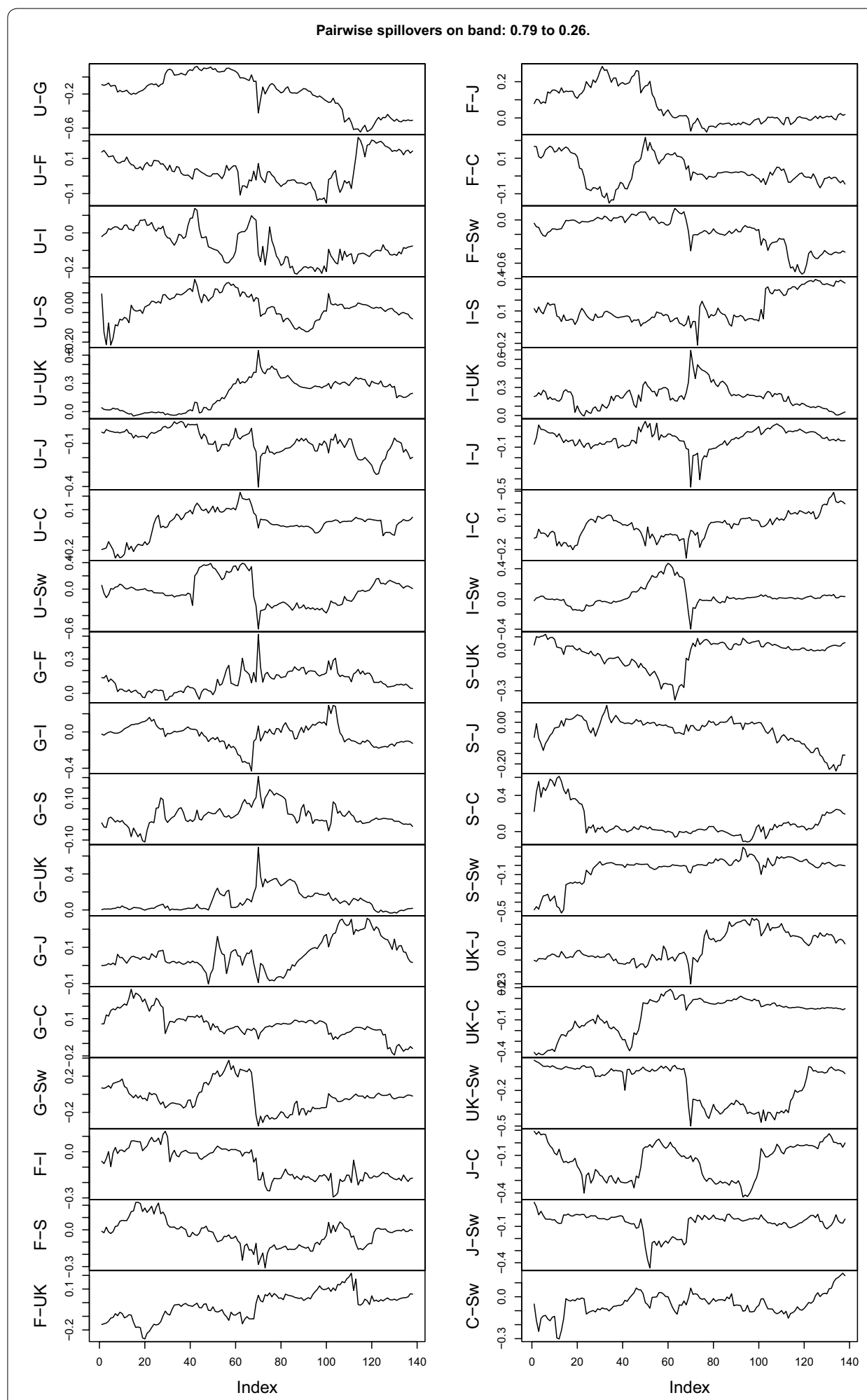

Fig. $1510 y 12 m-B K 4$ to 12 months 

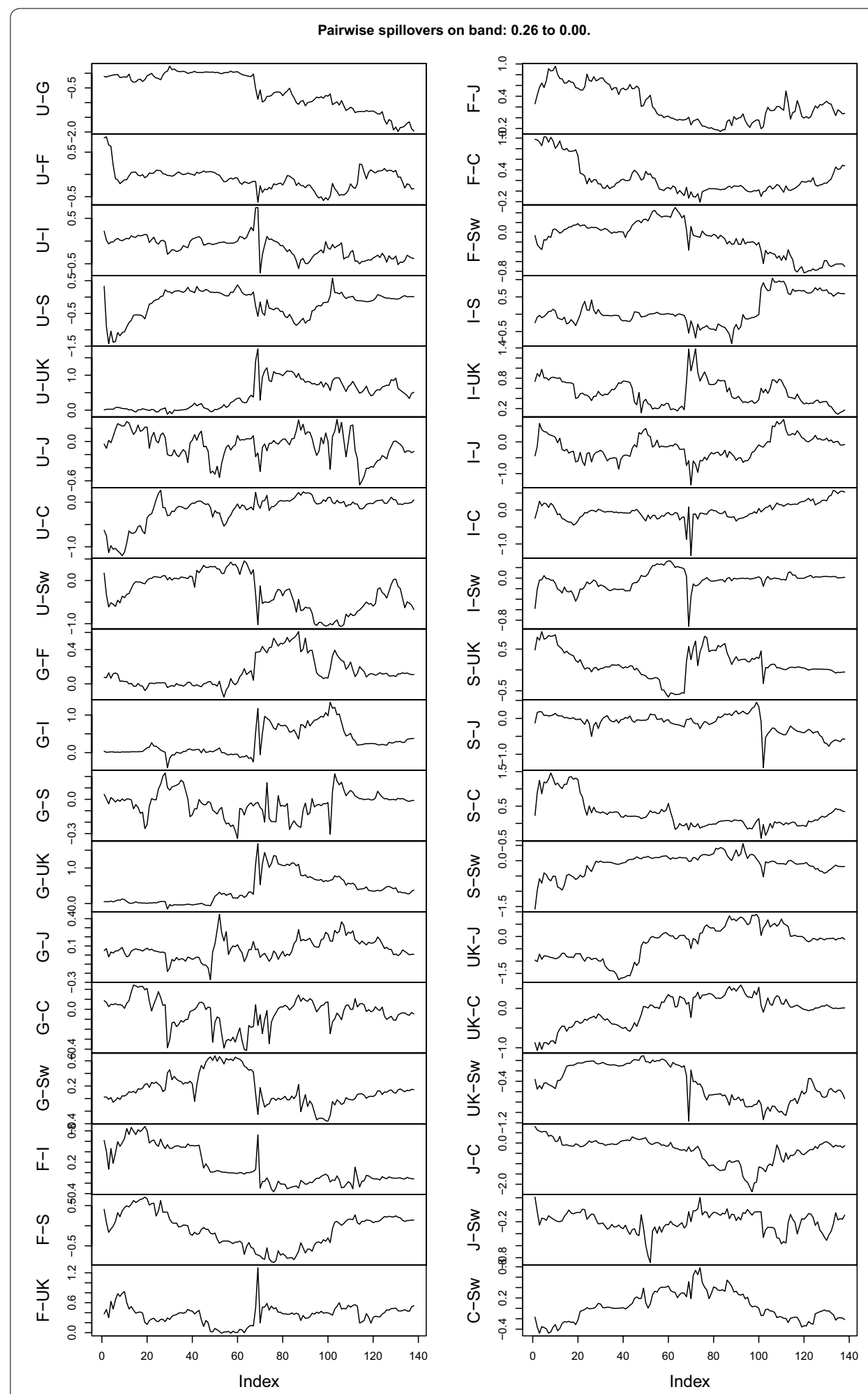

Fig. $1610 y 12$ m—BK 12 months+ 
relatively unstudied is the exact transmission mechanisms through which monetary policy uncertainty spills over.

\section{Abbreviations}

BK: Baruník and Křehlík (2018); DY: Diebold and Yilmaz (2009, 2012, 2015); U: United States of America; G: Germany; F: France; I: Italy; S: Spain; UK: United Kingdom; J: Japan; C: Canada; Sw: Sweden.

\section{Acknowledgements}

We would like to thank three anonymous referees for many helpful comments. However, any remaining errors are solely ours.

\section{Authors' contributions}

All the authors have equally contributed to designing the study, studying concepts or design, dealing with data collection, and calculation so as to write the manuscript. All authors read and approved the final manuscript.

\section{Funding}

Not available.

\section{Availability of data and materials}

Istrefi, K., \& Mouabbi, S. Subjective interest rate uncertainty and the macroeconomy: A cross-country analysis (2018). https://sites.google.com/site/istrefiklodiana/interest-rate-uncertainty?authuser=1

Ethics approval and consent to participate

No primary data were used.

\section{Consent for publication}

Not applicable.

\section{Competing interests}

The authors declare that they have no competing interests.

\section{Author details}

${ }^{1}$ Department of Economics, University of Pretoria, Pretoria 0002, South Africa. ${ }^{2}$ Huddersfield Business School, University of Huddersfield, Huddersfield HD1 3DH, United Kingdom. ${ }^{3}$ University of Pretoria, Pretoria 0002, South Africa. ${ }^{4}$ Lord Ashcroft International Business School, Anglia Ruskin University, Chelmsford CM1 1SQ, UK.

\section{Appendix}

Table 3 3m3m DY

\begin{tabular}{lrrrrrrrrrr}
\hline & U & \multicolumn{1}{l}{ G } & \multicolumn{1}{l}{ F } & \multicolumn{1}{c}{ I } & \multicolumn{1}{c}{ S } & \multicolumn{1}{c}{ UK } & J & C & Sw & FROM \\
\hline U & 60.71 & 3.25 & 5.23 & 0.49 & 4.24 & 2.01 & 1.89 & 17.16 & 5.02 & 4.37 \\
G & 9.02 & 18.74 & 15.65 & 17.45 & 19.19 & 2.86 & 0.89 & 15.49 & 0.70 & 9.03 \\
F & 8.83 & 11.85 & 23.88 & 17.57 & 18.85 & 2.03 & 0.85 & 15.36 & 0.77 & 8.46 \\
I & 4.11 & 10.12 & 14.44 & 30.78 & 21.22 & 2.79 & 0.63 & 14.35 & 1.56 & 7.69 \\
S & 5.76 & 9.70 & 14.64 & 21.44 & 27.87 & 4.62 & 0.72 & 14.50 & 0.75 & 8.01 \\
UK & 7.28 & 5.82 & 9.62 & 14.82 & 20.80 & 24.77 & 0.72 & 15.20 & 0.98 & 8.36 \\
J & 3.75 & 5.21 & 8.21 & 9.09 & 14.36 & 9.39 & 41.85 & 7.03 & 1.11 & 6.46 \\
C & 19.56 & 2.89 & 4.24 & 7.61 & 7.29 & 2.15 & 3.61 & 51.67 & 0.99 & 5.37 \\
SW & 4.45 & 7.03 & 13.50 & 18.51 & 16.32 & 2.53 & 0.65 & 12.67 & 24.34 & 8.41 \\
TO & 6.97 & 6.21 & 9.50 & 11.89 & 13.59 & 3.15 & 1.11 & 12.42 & 1.32 & 66.15 \\
\hline
\end{tabular}

Entry $i, j(i \neq j)$ represents the estimated contribution to the forecast error variance of country $j$ coming from shocks in country $i$. The diagonal element $(i=j)$ captures the fraction of the forecast error variance of country $i$ due to its own shocks. The elements in the last row (labeled "TO") represent directional spillovers transmitted by country $i$ (column) to all other countries, and those in the last column (labeled "FROM") are directional spillovers received by country $j$ (row) from all other countries 
Table 4 3m3m BK

\begin{tabular}{|c|c|c|c|c|c|c|c|c|c|c|c|}
\hline & u & G & $F$ & 1 & 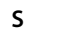 & UK & J & C & Sw & FROM ABS & FROM WTH \\
\hline \multicolumn{12}{|c|}{ Panel A-1 to 4 months } \\
\hline U & 14.06 & 1.14 & 1.14 & 0.11 & 0.82 & 0.32 & 0.57 & 1.04 & 0.31 & 0.61 & 3.09 \\
\hline G & 0.45 & 6.26 & 2.25 & 1.59 & 2.20 & 0.33 & 0.17 & 0.60 & 0.22 & 0.87 & 4.41 \\
\hline F & 0.27 & 2.53 & 6.41 & 2.21 & 3.31 & 0.39 & 0.04 & 0.62 & 0.13 & 1.06 & 5.37 \\
\hline 1 & 0.04 & 2.40 & 2.72 & 8.24 & 4.29 & 0.77 & 0.01 & 0.99 & 0.30 & 1.28 & 6.51 \\
\hline S & 0.22 & 2.30 & 3.42 & 3.85 & 8.75 & 1.60 & 0.19 & 1.10 & 0.13 & 1.42 & 7.25 \\
\hline UK & 0.30 & 0.88 & 1.79 & 1.50 & 3.70 & 7.79 & 0.27 & 0.78 & 0.23 & 1.05 & 5.35 \\
\hline J & 0.72 & 0.30 & 0.52 & 0.10 & 0.33 & 0.47 & 11.84 & 2.30 & 0.11 & 0.54 & 2.74 \\
\hline C & 0.82 & 0.22 & 0.56 & 2.29 & 1.04 & 0.49 & 2.35 & 19.73 & 0.26 & 0.89 & 4.54 \\
\hline Sw & 0.67 & 1.21 & 2.78 & 2.56 & 2.92 & 0.34 & 0.13 & 1.00 & 12.75 & 1.29 & 6.56 \\
\hline TOABS & 0.39 & 1.22 & 1.69 & 1.58 & 2.07 & 0.52 & 0.41 & 0.94 & 0.19 & 9.01 & \\
\hline TOWTH & 1.98 & 6.20 & 8.58 & 8.03 & 10.52 & 2.67 & 2.11 & 4.77 & 0.96 & & 45.82 \\
\hline \multicolumn{12}{|c|}{ Panel B-4 to 12 months } \\
\hline U & 12.32 & 0.96 & 1.77 & 0.27 & 1.23 & 0.25 & 0.65 & 4.34 & 0.69 & 1.13 & 6.19 \\
\hline G & 0.57 & 3.46 & 3.03 & 3.80 & 3.72 & 0.35 & 0.03 & 2.12 & 0.19 & 1.53 & 8.43 \\
\hline $\mathrm{F}$ & 0.62 & 2.29 & 4.86 & 3.87 & 3.39 & 0.14 & 0.13 & 2.11 & 0.27 & 1.42 & 7.82 \\
\hline । & 0.10 & 1.48 & 2.32 & 5.91 & 3.65 & 0.33 & 0.02 & 1.79 & 0.47 & 1.13 & 6.20 \\
\hline s & 0.33 & 1.82 & 2.80 & 5.11 & 5.54 & 0.88 & 0.04 & 2.23 & 0.21 & 1.49 & 8.19 \\
\hline UK & 0.78 & 1.28 & 2.08 & 4.02 & 5.19 & 7.07 & 0.06 & 2.76 & 0.31 & 1.83 & 10.05 \\
\hline J & 0.21 & 0.66 & 0.97 & 0.93 & 1.61 & 1.36 & 8.11 & 0.14 & 0.38 & 0.69 & 3.82 \\
\hline C & 3.04 & 0.55 & 0.57 & 1.56 & 1.12 & 0.11 & 0.56 & 8.25 & 0.15 & 0.85 & 4.67 \\
\hline Sw & 0.19 & 1.10 & 2.38 & 3.86 & 2.71 & 0.48 & 0.10 & 1.69 & 5.11 & 1.39 & 7.63 \\
\hline TOABS & 0.65 & 1.12 & 1.77 & 2.60 & 2.51 & 0.43 & 0.18 & 1.91 & 0.30 & 11.47 & \\
\hline TOWTH & 3.56 & 6.18 & 9.71 & 14.29 & 13.80 & 2.38 & 0.96 & 10.48 & 1.63 & & 63.00 \\
\hline \multicolumn{12}{|c|}{ Panel C - 12 months + } \\
\hline$u$ & 34.33 & 1.15 & 2.32 & 0.10 & 2.19 & 1.43 & 0.67 & 11.79 & 4.02 & 2.63 & 4.23 \\
\hline G & 8.00 & 9.02 & 10.37 & 12.07 & 13.28 & 2.17 & 0.69 & 12.77 & 0.30 & 6.63 & 10.67 \\
\hline $\mathrm{F}$ & 7.94 & 7.04 & 12.61 & 11.49 & 12.16 & 1.49 & 0.68 & 12.63 & 0.38 & 5.98 & 9.62 \\
\hline I & 3.97 & 6.24 & 9.40 & 16.64 & 13.28 & 1.69 & 0.60 & 11.57 & 0.79 & 5.28 & 8.50 \\
\hline S & 5.20 & 5.58 & 8.43 & 12.49 & 13.58 & 2.14 & 0.49 & 11.18 & 0.40 & 5.10 & 8.21 \\
\hline UK & 6.20 & 3.67 & 5.75 & 9.30 & 11.91 & 9.90 & 0.39 & 11.65 & 0.43 & 5.48 & 8.82 \\
\hline J & 2.82 & 4.25 & 6.72 & 8.07 & 12.42 & 7.56 & 21.89 & 4.58 & 0.62 & 5.23 & 8.41 \\
\hline C & 15.70 & 2.11 & 3.11 & 3.76 & 5.13 & 1.55 & 0.69 & 23.70 & 0.58 & 3.63 & 5.83 \\
\hline Sw & 3.60 & 4.73 & 8.35 & 12.09 & 10.68 & 1.71 & 0.42 & 9.98 & 6.48 & 5.73 & 9.22 \\
\hline TOABS & 5.94 & 3.86 & 6.05 & 7.71 & 9.01 & 2.19 & 0.52 & 9.57 & 0.84 & 45.68 & \\
\hline TOWTH & 9.55 & 6.22 & 9.73 & 12.40 & 14.49 & 3.53 & 0.83 & 15.40 & 1.34 & & 73.51 \\
\hline
\end{tabular}

See note to Table 3

Table $53 \mathrm{~m} 12 \mathrm{~m}$ DY

\begin{tabular}{lrrrrrrrrrr}
\hline & U & \multicolumn{1}{c}{ G } & \multicolumn{1}{c}{ F } & I & \multicolumn{1}{c}{ S } & UK & J & C & Sw & FROM \\
\hline U & 74.64 & 6.99 & 2.19 & 7.61 & 2.75 & 2.08 & 1.22 & 0.91 & 1.63 & 2.82 \\
G & 22.05 & 36.86 & 10.41 & 1.83 & 16.01 & 5.88 & 1.42 & 1.97 & 3.58 & 7.02 \\
F & 6.73 & 15.49 & 47.49 & 6.45 & 13.68 & 4.77 & 2.65 & 0.63 & 2.11 & 5.83 \\
I & 2.96 & 6.73 & 8.44 & 59.35 & 15.28 & 1.29 & 3.62 & 1.56 & 0.76 & 4.52 \\
S & 6.33 & 12.04 & 12.24 & 7.51 & 51.35 & 3.89 & 1.01 & 3.97 & 1.65 & 5.41 \\
UK & 20.86 & 17.54 & 4.44 & 0.91 & 10.97 & 37.22 & 1.58 & 2.82 & 3.68 & 6.98 \\
J & 2.12 & 0.88 & 2.54 & 1.32 & 1.48 & 5.74 & 80.75 & 4.53 & 0.65 & 2.14 \\
C & 23.24 & 4.16 & 1.76 & 0.99 & 5.38 & 0.64 & 0.35 & 62.98 & 0.52 & 4.11 \\
SW & 7.70 & 8.84 & 7.38 & 1.06 & 9.13 & 5.00 & 0.73 & 1.30 & 58.87 & 4.57 \\
TO & 10.22 & 8.07 & 5.49 & 3.07 & 8.30 & 3.25 & 1.40 & 1.96 & 1.62 & 43.39 \\
\hline
\end{tabular}

See note to Table 3 
Table 6 3m12m BK

\begin{tabular}{|c|c|c|c|c|c|c|c|c|c|c|c|}
\hline & $u$ & G & $\mathrm{F}$ & 1 & $\mathrm{~s}$ & UK & J & C & Sw & FROMABS & FROMWTH \\
\hline \multicolumn{12}{|c|}{ Panel $A-1$ to 4 months } \\
\hline U & 12.75 & 1.36 & 0.55 & 0.31 & 0.69 & 0.62 & 0.31 & 0.08 & 0.39 & 0.48 & 1.60 \\
\hline G & 0.79 & 9.66 & 2.83 & 0.80 & 1.30 & 0.89 & 0.21 & 0.18 & 0.92 & 0.88 & 2.95 \\
\hline $\mathrm{F}$ & 0.80 & 8.41 & 31.04 & 3.06 & 5.28 & 1.95 & 0.47 & 0.41 & 1.86 & 2.47 & 8.26 \\
\hline 1 & 0.54 & 1.73 & 3.43 & 27.65 & 2.28 & 0.81 & 1.51 & 0.46 & 0.57 & 1.26 & 4.21 \\
\hline S & 0.93 & 2.55 & 4.08 & 1.74 & 17.98 & 0.93 & 0.06 & 0.16 & 0.86 & 1.26 & 4.21 \\
\hline UK & 0.37 & 0.75 & 0.68 & 0.24 & 0.70 & 10.47 & 0.18 & 0.07 & 0.40 & 0.38 & 1.26 \\
\hline J & 0.07 & 0.36 & 0.60 & 0.39 & 0.05 & 0.36 & 17.74 & 0.42 & 0.56 & 0.31 & 1.04 \\
\hline c & 0.50 & 0.19 & 0.48 & 0.11 & 0.93 & 0.26 & 0.04 & 23.62 & 0.35 & 0.32 & 1.06 \\
\hline Sw & 0.79 & 3.79 & 4.23 & 0.76 & 1.81 & 2.20 & 0.19 & 0.19 & 38.07 & 1.55 & 5.18 \\
\hline TOABS & 0.53 & 2.12 & 1.87 & 0.82 & 1.45 & 0.89 & 0.33 & 0.22 & 0.66 & 8.90 & \\
\hline TOWTH & 1.78 & 7.11 & 6.27 & 2.75 & 4.85 & 2.99 & 1.10 & 0.73 & 2.20 & & 29.76 \\
\hline \multicolumn{12}{|c|}{ Panel B-4 to 12 months } \\
\hline U & 18.30 & 2.01 & 0.74 & 1.21 & 1.03 & 0.32 & 0.12 & 0.29 & 0.44 & 0.69 & 3.40 \\
\hline G & 3.08 & 7.58 & 2.07 & 0.49 & 3.83 & 1.13 & 0.09 & 0.38 & 0.88 & 1.33 & 6.58 \\
\hline $\mathrm{F}$ & 0.98 & 2.37 & 8.17 & 2.06 & 3.56 & 0.80 & 0.42 & 0.15 & 0.17 & 1.17 & 5.79 \\
\hline । & 0.31 & 0.91 & 1.44 & 14.65 & 3.13 & 0.07 & 0.14 & 0.43 & 0.13 & 0.73 & 3.60 \\
\hline s & 0.40 & 1.98 & 2.98 & 2.10 & 10.87 & 0.65 & 0.11 & 0.62 & 0.32 & 1.02 & 5.05 \\
\hline UK & 2.09 & 2.95 & 0.63 & 0.25 & 1.83 & 9.65 & 0.18 & 0.33 & 0.87 & 1.01 & 5.02 \\
\hline J & 0.44 & 0.18 & 0.57 & 0.45 & 0.24 & 1.00 & 15.45 & 0.34 & 0.06 & 0.36 & 1.81 \\
\hline C & 2.82 & 0.66 & 0.84 & 0.04 & 0.65 & 0.01 & 0.12 & 12.75 & 0.07 & 0.58 & 2.88 \\
\hline Sw & 1.75 & 2.15 & 1.48 & 0.16 & 3.32 & 1.24 & 0.08 & 0.33 & 11.63 & 1.17 & 5.80 \\
\hline TOABS & 1.32 & 1.47 & 1.19 & 0.75 & 1.96 & 0.58 & 0.14 & 0.32 & 0.33 & 8.05 & \\
\hline TOWTH & 6.54 & 7.28 & 5.92 & 3.72 & 9.69 & 2.88 & 0.70 & 1.58 & 1.62 & & 39.92 \\
\hline \multicolumn{12}{|c|}{ Panel C - 12 months + } \\
\hline u & 43.59 & 3.61 & 0.90 & 6.09 & 1.02 & 1.14 & 0.79 & 0.54 & 0.79 & 1.65 & 3.31 \\
\hline G & 18.18 & 19.61 & 5.50 & 0.54 & 10.88 & 3.86 & 1.12 & 1.42 & 1.78 & 4.81 & 9.63 \\
\hline $\mathrm{F}$ & 4.95 & 4.71 & 8.28 & 1.33 & 4.84 & 2.02 & 1.77 & 0.07 & 0.08 & 2.20 & 4.40 \\
\hline 1 & 2.12 & 4.10 & 3.58 & 17.06 & 9.87 & 0.41 & 1.97 & 0.68 & 0.06 & 2.53 & 5.07 \\
\hline S & 5.00 & 7.52 & 5.18 & 3.67 & 22.50 & 2.30 & 0.85 & 3.18 & 0.47 & 3.13 & 6.27 \\
\hline UK & 18.39 & 13.84 & 3.14 & 0.42 & 8.44 & 17.10 & 1.21 & 2.43 & 2.41 & 5.59 & 11.19 \\
\hline J & 1.62 & 0.34 & 1.38 & 0.48 & 1.18 & 4.37 & 47.56 & 3.77 & 0.02 & 1.46 & 2.93 \\
\hline C & 19.91 & 3.31 & 0.44 & 0.84 & 3.80 & 0.36 & 0.19 & 26.61 & 0.11 & 3.22 & 6.44 \\
\hline Sw & 5.17 & 2.90 & 1.67 & 0.14 & 4.00 & 1.55 & 0.46 & 0.78 & 9.16 & 1.85 & 3.71 \\
\hline TOABS & 8.37 & 4.48 & 2.42 & 1.50 & 4.89 & 1.78 & 0.93 & 1.43 & 0.64 & 26.44 & \\
\hline TOWTH & 16.76 & 8.97 & 4.85 & 3.01 & 9.80 & 3.57 & 1.86 & 2.86 & 1.27 & & 52.95 \\
\hline
\end{tabular}

See note to Table 3

Table 7 10y3m DY

\begin{tabular}{|c|c|c|c|c|c|c|c|c|c|c|}
\hline & U & G & $F$ & I & $S$ & UK & J & $C$ & Sw & FROM \\
\hline U & 65.14 & 3.70 & 6.02 & 2.09 & 3.11 & 4.84 & 1.46 & 5.12 & 8.54 & 3.87 \\
\hline G & 1.29 & 51.22 & 3.95 & 2.22 & 0.35 & 16.08 & 0.13 & 4.98 & 19.77 & 5.42 \\
\hline F & 3.88 & 3.08 & 54.18 & 4.68 & 21.29 & 3.13 & 0.73 & 1.56 & 7.46 & 5.09 \\
\hline 1 & 3.34 & 2.35 & 24.47 & 31.64 & 24.06 & 1.46 & 0.30 & 2.05 & 10.33 & 7.60 \\
\hline S & 2.48 & 0.69 & 19.16 & 4.56 & 63.11 & 1.19 & 0.73 & 2.24 & 5.85 & 4.10 \\
\hline UK & 2.24 & 16.31 & 3.90 & 0.87 & 0.95 & 53.06 & 1.22 & 9.76 & 11.69 & 5.22 \\
\hline J & 2.78 & 0.33 & 1.87 & 0.12 & 1.63 & 2.97 & 87.63 & 0.46 & 2.21 & 1.37 \\
\hline C & 5.64 & 6.91 & 1.42 & 0.93 & 1.51 & 12.16 & 1.12 & 64.44 & 5.86 & 3.95 \\
\hline Sw & 1.65 & 18.33 & 7.24 & 3.44 & 3.93 & 11.47 & 0.47 & 4.15 & 49.32 & 5.63 \\
\hline TO & 2.59 & 5.75 & 7.56 & 2.10 & 6.32 & 5.92 & 0.68 & 3.37 & 7.97 & 42.25 \\
\hline
\end{tabular}

See note to Table 3 
Table 8 10y3m BK

\begin{tabular}{|c|c|c|c|c|c|c|c|c|c|c|c|}
\hline & u & G & $\mathrm{F}$ & I & $S$ & UK & J & C & Sw & FROMABS & FROMWTH \\
\hline \multicolumn{12}{|c|}{ Panel A-1 to 4 months } \\
\hline U & 27.08 & 0.64 & 2.15 & 0.39 & 1.63 & 0.76 & 0.35 & 1.29 & 0.91 & 0.90 & 1.83 \\
\hline G & 0.90 & 36.68 & 1.93 & 1.21 & 0.23 & 11.35 & 0.09 & 3.44 & 14.67 & 3.76 & 7.64 \\
\hline $\mathrm{F}$ & 1.11 & 1.35 & 20.30 & 1.47 & 4.15 & 1.56 & 0.41 & 0.46 & 2.47 & 1.44 & 2.94 \\
\hline 1 & 0.22 & 0.26 & 0.92 & 9.65 & 1.18 & 0.06 & 0.02 & 0.25 & 0.51 & 0.38 & 0.77 \\
\hline S & 1.10 & 0.17 & 6.67 & 1.31 & 35.46 & 0.12 & 0.39 & 0.65 & 2.21 & 1.40 & 2.85 \\
\hline UK & 1.29 & 11.35 & 1.99 & 0.30 & 0.24 & 34.23 & 0.26 & 5.85 & 7.69 & 3.22 & 6.55 \\
\hline J & 0.45 & 0.24 & 1.15 & 0.11 & 0.54 & 0.40 & 43.07 & 0.23 & 1.31 & 0.49 & 1.00 \\
\hline C & 2.06 & 4.87 & 1.10 & 0.68 & 0.97 & 7.67 & 0.98 & 49.01 & 2.65 & 2.33 & 4.74 \\
\hline Sw & 1.02 & 12.64 & 3.52 & 1.48 & 1.98 & 6.38 & 0.25 & 2.01 & 32.39 & 3.25 & 6.62 \\
\hline TOABS & 0.91 & 3.50 & 2.16 & 0.77 & 1.21 & 3.14 & 0.31 & 1.57 & 3.60 & 17.18 & \\
\hline TOWTH & 1.84 & 7.12 & 4.39 & 1.57 & 2.47 & 6.39 & 0.62 & 3.20 & 7.33 & & 34.94 \\
\hline \multicolumn{12}{|c|}{ Panel B-4 to 12 months } \\
\hline$U$ & 18.91 & 1.47 & 2.06 & 0.73 & 0.93 & 1.73 & 0.51 & 1.63 & 3.17 & 1.36 & 6.41 \\
\hline G & 0.25 & 9.15 & 1.03 & 0.58 & 0.03 & 2.92 & 0.03 & 0.96 & 3.07 & 0.99 & 4.66 \\
\hline $\mathrm{F}$ & 0.81 & 0.64 & 13.55 & 0.90 & 6.01 & 0.37 & 0.23 & 0.28 & 1.45 & 1.19 & 5.61 \\
\hline 1 & 0.69 & 0.55 & 5.27 & 7.26 & 5.51 & 0.15 & 0.08 & 0.41 & 2.22 & 1.65 & 7.81 \\
\hline S & 0.29 & 0.11 & 2.95 & 0.75 & 9.92 & 0.20 & 0.10 & 0.44 & 0.66 & 0.61 & 2.88 \\
\hline UK & 0.55 & 3.05 & 0.56 & 0.20 & 0.12 & 10.73 & 0.33 & 2.04 & 1.79 & 0.96 & 4.54 \\
\hline J & 0.75 & 0.02 & 0.40 & 0.00 & 0.35 & 1.11 & 20.69 & 0.12 & 0.53 & 0.37 & 1.72 \\
\hline C & 1.98 & 1.22 & 0.17 & 0.12 & 0.30 & 2.27 & 0.08 & 9.03 & 1.35 & 0.83 & 3.93 \\
\hline Sw & 0.40 & 3.49 & 1.36 & 0.91 & 0.56 & 2.66 & 0.16 & 1.09 & 9.13 & 1.18 & 5.58 \\
\hline TOABS & 0.64 & 1.17 & 1.53 & 0.47 & 1.54 & 1.27 & 0.17 & 0.77 & 1.58 & 9.14 & \\
\hline TOWTH & 3.00 & 5.53 & 7.25 & 2.20 & 7.25 & 5.98 & 0.79 & 3.66 & 7.47 & & 43.14 \\
\hline \multicolumn{12}{|c|}{ Panel C_-12 months + } \\
\hline U & 19.14 & 1.60 & 1.81 & 0.97 & 0.55 & 2.34 & 0.60 & 2.21 & 4.45 & 1.61 & 5.44 \\
\hline G & 0.14 & 5.39 & 0.99 & 0.43 & 0.09 & 1.82 & 0.02 & 0.58 & 2.02 & 0.68 & 2.28 \\
\hline $\mathrm{F}$ & 1.95 & 1.08 & 20.33 & 2.31 & 11.13 & 1.20 & 0.08 & 0.82 & 3.54 & 2.46 & 8.29 \\
\hline 1 & 2.43 & 1.55 & 18.27 & 14.73 & 17.37 & 1.25 & 0.20 & 1.39 & 7.60 & 5.56 & 18.76 \\
\hline S & 1.09 & 0.41 & 9.54 & 2.49 & 17.72 & 0.87 & 0.24 & 1.16 & 2.98 & 2.09 & 7.04 \\
\hline UK & 0.40 & 1.90 & 1.35 & 0.37 & 0.59 & 8.09 & 0.63 & 1.87 & 2.21 & 1.04 & 3.49 \\
\hline J & 1.58 & 0.07 & 0.32 & 0.01 & 0.74 & 1.46 & 23.87 & 0.12 & 0.38 & 0.52 & 1.75 \\
\hline C & 1.60 & 0.83 & 0.15 & 0.13 & 0.24 & 2.23 & 0.06 & 6.40 & 1.86 & 0.79 & 2.66 \\
\hline SW & 0.22 & 2.20 & 2.35 & 1.05 & 1.40 & 2.44 & 0.06 & 1.05 & 7.81 & 1.20 & 4.03 \\
\hline TOABS & 1.05 & 1.07 & 3.86 & 0.86 & 3.57 & 1.51 & 0.21 & 1.02 & 2.78 & 15.94 & \\
\hline TOWTH & 3.53 & 3.61 & 13.03 & 2.90 & 12.03 & 5.10 & 0.71 & 3.44 & 9.38 & & 53.74 \\
\hline
\end{tabular}

See note to Table 3

Table 9 10y12m DY

\begin{tabular}{lrrrrrrrrrrr}
\hline & U & G & F & I & S & UK & J & C & Sw & FROM \\
\hline U & 71.18 & 6.59 & 2.45 & 1.59 & 2.10 & 9.62 & 0.93 & 0.76 & 4.78 & 3.20 \\
G & 17.17 & 69.16 & 1.86 & 4.50 & 0.57 & 3.92 & 0.44 & 1.72 & 0.67 & 3.43 \\
F & 5.65 & 0.85 & 59.43 & 5.74 & 6.80 & 12.09 & 1.39 & 3.55 & 4.49 & 4.51 \\
I & 4.84 & 5.30 & 7.03 & 55.29 & 12.31 & 11.70 & 0.29 & 1.01 & 2.23 & 4.97 \\
S & 3.70 & 0.36 & 2.03 & 4.35 & 62.54 & 3.10 & 1.16 & 12.11 & 10.65 & 4.16 \\
UK & 5.71 & 2.29 & 8.13 & 2.28 & 0.52 & 74.55 & 2.84 & 1.33 & 2.35 & 2.83 \\
J & 2.41 & 0.40 & 0.42 & 0.87 & 1.16 & 3.13 & 81.48 & 8.63 & 1.49 & 2.06 \\
C & 4.30 & 0.68 & 0.90 & 0.28 & 2.99 & 0.99 & 2.85 & 82.45 & 4.56 & 1.95 \\
SW & 6.65 & 1.49 & 3.64 & 3.56 & 19.40 & 6.55 & 1.44 & 4.86 & 52.41 & 5.29 \\
TO & 5.60 & 2.00 & 2.94 & 2.57 & 5.09 & 5.68 & 1.26 & 3.78 & 3.47 & 32.39 \\
\hline
\end{tabular}

See note to Table 3 
Table 10 10y12m BK

\begin{tabular}{|c|c|c|c|c|c|c|c|c|c|c|c|}
\hline & U & G & $\mathrm{F}$ & 1 & $S$ & UK & $J$ & $\mathrm{C}$ & Sw & FROMABS & FROMWTH \\
\hline \multicolumn{12}{|c|}{ Panel $A-1$ to 4 months } \\
\hline U & 18.51 & 1.68 & 1.11 & 0.18 & 0.15 & 1.05 & 0.4 & 0.37 & 0.49 & 0.6 & 1.85 \\
\hline G & 1.73 & 23.7 & 0.4 & 0.59 & 0.11 & 0.85 & 0.14 & 0.47 & 0.27 & 0.51 & 1.55 \\
\hline $\mathrm{F}$ & 1.22 & 0.49 & 27.07 & 1.84 & 1.21 & 3.13 & 0.33 & 0.5 & 1.01 & 1.08 & 3.3 \\
\hline I & 0.7 & 2.46 & 1.64 & 22.2 & 1.05 & 0.73 & 0.09 & 0.38 & 0.34 & 0.82 & 2.51 \\
\hline S & 0.18 & 0.34 & 1.52 & 1.26 & 25.89 & 0.06 & 0.61 & 0.34 & 2.09 & 0.71 & 2.18 \\
\hline UK & 2.8 & 1.71 & 4 & 1.01 & 0.18 & 42.04 & 1.91 & 0.48 & 1.65 & 1.53 & 4.67 \\
\hline J & 0.88 & 0.08 & 0.14 & 0.04 & 0.12 & 1.24 & 31.95 & 1.86 & 0.77 & 0.57 & 1.74 \\
\hline C & 0.4 & 0.64 & 0.5 & 0.02 & 0.18 & 0.06 & 0.81 & 24.71 & 0.24 & 0.32 & 0.97 \\
\hline Sw & 0.42 & 0.39 & 0.79 & 0.5 & 1.16 & 0.92 & 0.28 & 0.07 & 18.15 & 0.5 & 1.54 \\
\hline TOABS & 0.92 & 0.86 & 1.12 & 0.6 & 0.46 & 0.89 & 0.51 & 0.5 & 0.76 & 6.64 & \\
\hline TOWTH & 2.83 & 2.65 & 3.44 & 1.85 & 1.41 & 2.73 & 1.56 & 1.52 & 2.33 & & 20.32 \\
\hline \multicolumn{12}{|c|}{ Panel B-4 to 12 months } \\
\hline U & 15.99 & 1.95 & 0.76 & 0.29 & 0.28 & 2.28 & 0.24 & 0.25 & 1.06 & 0.79 & 3.49 \\
\hline G & 4.17 & 21.19 & 0.41 & 1.00 & 0.31 & 0.45 & 0.18 & 0.56 & 0.09 & 0.80 & 3.51 \\
\hline $\mathrm{F}$ & 0.70 & 0.23 & 14.72 & 0.88 & 0.69 & 1.90 & 0.46 & 0.37 & 0.50 & 0.64 & 2.82 \\
\hline I & 0.88 & 1.89 & 1.47 & 12.40 & 1.92 & 2.60 & 0.07 & 0.08 & 0.32 & 1.03 & 4.53 \\
\hline S & 0.55 & 0.01 & 0.25 & 0.49 & 11.34 & 0.41 & 0.20 & 2.81 & 1.24 & 0.66 & 2.92 \\
\hline UK & 1.02 & 0.44 & 1.54 & 0.47 & 0.09 & 16.25 & 0.76 & 0.32 & 0.54 & 0.58 & 2.54 \\
\hline J & 0.64 & 0.10 & 0.21 & 0.15 & 0.37 & 0.58 & 21.68 & 1.15 & 0.14 & 0.37 & 1.64 \\
\hline C & 0.88 & 0.02 & 0.29 & 0.01 & 0.22 & 0.18 & 0.69 & 24.19 & 0.78 & 0.34 & 1.51 \\
\hline Sw & 0.75 & 0.57 & 1.08 & 0.54 & 3.20 & 0.80 & 0.34 & 0.50 & 11.42 & 0.86 & 3.82 \\
\hline TOABS & 1.07 & 0.58 & 0.67 & 0.43 & 0.79 & 1.02 & 0.33 & 0.67 & 0.52 & 6.06 & \\
\hline TOWTH & 4.71 & 2.56 & 2.94 & 1.88 & 3.47 & 4.51 & 1.44 & 2.97 & 2.29 & & 26.78 \\
\hline \multicolumn{12}{|c|}{ Panel C - 12 months + } \\
\hline U & 36.68 & 2.96 & 0.58 & 1.12 & 1.66 & 6.28 & 0.29 & 0.14 & 3.24 & 1.81 & 4.04 \\
\hline G & 11.27 & 24.27 & 1.05 & 2.91 & 0.16 & 2.62 & 0.12 & 0.69 & 0.31 & 2.13 & 4.75 \\
\hline $\mathrm{F}$ & 3.73 & 0.13 & 17.65 & 3.02 & 4.91 & 7.06 & 0.60 & 2.68 & 2.98 & 2.79 & 6.24 \\
\hline । & 3.26 & 0.95 & 3.92 & 20.69 & 9.34 & 8.37 & 0.13 & 0.54 & 1.57 & 3.12 & 6.98 \\
\hline S & 2.97 & 0.01 & 0.26 & 2.61 & 25.32 & 2.64 & 0.35 & 8.96 & 7.32 & 2.79 & 6.24 \\
\hline UK & 1.89 & 0.14 & 2.60 & 0.80 & 0.25 & 16.25 & 0.16 & 0.53 & 0.16 & 0.73 & 1.62 \\
\hline J & 0.89 & 0.22 & 0.08 & 0.68 & 0.67 & 1.31 & 27.85 & 5.62 & 0.58 & 1.12 & 2.50 \\
\hline C & 3.01 & 0.03 & 0.10 & 0.24 & 2.59 & 0.76 & 1.35 & 33.56 & 3.54 & 1.29 & 2.89 \\
\hline Sw & 5.48 & 0.54 & 1.77 & 2.51 & 15.04 & 4.84 & 0.82 & 4.29 & 22.83 & 3.92 & 8.77 \\
\hline TOABS & 3.61 & 0.55 & 1.15 & 1.54 & 3.85 & 3.76 & 0.42 & 2.61 & 2.19 & 19.69 & \\
\hline TOWTH & 8.08 & 1.23 & 2.58 & 3.45 & 8.61 & 8.42 & 0.95 & 5.83 & 4.90 & & 44.05 \\
\hline
\end{tabular}

See note to Table 3

Received: 20 January 2020 Revised: 9 April 2020 Accepted: 15 May 2020

Published online: 22 May 2020

References

Ajmi AN, Gupta R, Kanda P (2014) Causality between economic policy uncertainty across countries: Evidence from linear and nonlinear tests. Front Finan Econ 11(1):73-102

Antonakakis N, Gabauer D, Gupta R (2018) Greek Economic Policy Uncertainty: Does it Matter for the European Union? University of Pretoria Department of Economics Working Paper Series, No. 201840

Antonakakis N, Gabauer D, Gupta R (2019) International monetary policy spillovers: evidence from a time-varying parameter vector autoregression. Int Rev Finan Anal 65:101382

Arbatli EC, Davis SJ, Ito A, Miake N, Saito I (2017) Policy uncertainty in Japan. NBER Working Paper Series, No. 23411 
Baker SR, Bloom N, Davis SJ (2016) Measuring economic policy uncertainty. Q J Econ 131(4):1593-1636

Balcilar M, Demirer R, Gupta R, Van Eyden R (2017a) The impact of US policy uncertainty on the monetary effectiveness in the Euro area. J Policy Model 39(6):1052-1064

Balcilar M, Gupta R, Jooste C (2017b) South Africa's economic response to monetary policy uncertainty. J Econ Stud 2:44

Balli F, Uddin GS, Mudassar H, Yoon SM (2017) Cross-country determinants of economic policy uncertainty spillovers. Econ Lett 156:179-183

Baruník J, Krehlík T (2018) Measuring the frequency dynamics of financial connectedness and systemic risk. J Financ Econ 16(2):271-296

Biljanovska N, Grigoli F, Hengge M (2017) Fear thy neighbor: spillovers from economic policy uncertainty. IMF Working Paper, WP/17/240

Caggiano G, Castelnuovo E, Figueres JM (2017) Economic policy uncertainty spillovers in booms and busts. CESifo Working Paper, No. 7086

Colombo V (2013) Economic policy uncertainty in the US: does it matter for the Euro area? Econ Lett 121(1):39-42

Çekin SE, Pradhan AK, Tiwari AK, Gupta R (2019) Measuring co-dependencies of economic policy uncertainty in Latin American Countries using vine copulas. Q Rev Econ Financ 2019:5

Diebold FX, Yilmaz K (2009) Measuring financial asset return and volatility spillovers, with application to global equity markets. Econ J 119(534):158-171

Diebold FX, Yilmaz K (2012) Better to give than to receive: predictive directional measurement of volatility spillovers. Int $J$ Forecast 28(1):57-66

Diebold FX, Yilmaz K (2015) Financial and macroeconomic connectedness: a network approach to measurement and monitoring. Oxford University Press, New York

Gabauer D, Gupta R (2018) On the transmission mechanism of country-specific and international economic uncertainty spillovers: evidence from a TVP-VAR connectedness decomposition approach. Econ Lett 171:63-71

Gabauer D, Gupta R (2020) Spillovers across macroeconomic, financial and real estate uncertainties: a time-varying approach. Struct Change Econ Dyn 52:167-173

Gupta R, Ma J, Risse M, Wohar ME (2018) Common business cycles and volatilities in US states and MSAs: the role of economic uncertainty. J Macroecon 57:317-337

Gupta R, Pierdzioch C, Risse M (2016) On international uncertainty links: BART-based empirical evidence for Canada. Econ Lett 143:24-27

Istrefi K, Mouabbi S (2018) Subjective interest rate uncertainty and the macroeconomy: a cross-country analysis. J Int Money Financ 88:296-313

Klößner S, Sekkel R (2014) International spillovers of policy uncertainty. Econ Lett 124(3):508-512

Liow KH, Liao WC, Huang Y (2018) Dynamics of international spillovers and interaction: evidence from financial market stress and economic policy uncertainty. Econ Model 68:96-116

Miranda-Agrippino S, Rey H (2015) World asset markets and the global financial cycle. NBER Working Paper Series, No. 21722

Nsafoah D, Serletis A (2019) International monetary policy spillovers. Open Econ Rev 30(1):87-104

Pesaran HH, Shin Y (1998) Generalized impulse response analysis in linear multivariate models. Econ Lett 58(1):17-29

Rey H (2015) Dilemma not trilemma: the global financial cycle and monetary policy independence. NBER Working Paper Series, No. 21162

Rey H (2016) International channels of transmission of monetary policy and the Mundellian trilemma. IMF Econ Rev 64(1):6-35

Tiwari AK, Cunado J, Gupta R, Wohar ME (2018) Volatility spillovers across global asset classes: evidence from time and frequency domains. Q Rev Econ Financ 70:194-202

Tran TD (2019) Measuring the macroeconomic impact of uncertainty. Doctoral dissertation

Yin L, Han L (2014) Spillovers of macroeconomic uncertainty among major economies. Appl Econ Lett 21(13):938-944

\section{Publisher's Note}

Springer Nature remains neutral with regard to jurisdictional claims in published maps and institutional affiliations.

\section{Submit your manuscript to a SpringerOpen ${ }^{\circ}$ journal and benefit from:}

- Convenient online submission

- Rigorous peer review

- Open access: articles freely available online

High visibility within the field

Retaining the copyright to your article

Submit your next manuscript at $\boldsymbol{\nabla}$ springeropen.com 